\title{
Incentivizing providers to improve maternal, newborn and child health services in Bangladesh: Pay-for-performance model refinement and advocacy (P4P MRA) final report
}

Md. Noorunnabi Talukder

Population Council

Ubaidur Rob

Population Council

Laila Rahman

Population Council

A.K.M. Zafar Ullah Khan

Population Council

Riad Mahmud

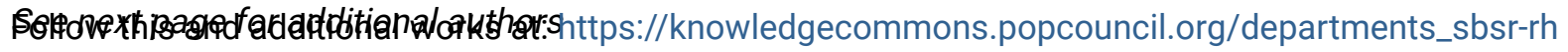

Part of the Demography, Population, and Ecology Commons, Family, Life Course, and Society Commons, Health Policy Commons, International Public Health Commons, Maternal and Child Health Commons, Public Health Education and Promotion Commons, and the Women's Health Commons How does access to this work benefit you? Let us know!

\section{Recommended Citation}

Talukder, Md. Noorunnabi, Ubaidur Rob, Laila Rahman, A.K.M. Zafar Ullah Khan, Riad Mahmud, Azizul Alim, Ismat Ara Hena, Farhana Akter, and Anup Kumar Dey. 2012. "Incentivizing providers to improve maternal, newborn and child health services in Bangladesh: Pay-for-performance model refinement and advocacy (P4P MRA) final report." Dhaka: Population Council. 


\section{Authors}

Md. Noorunnabi Talukder, Ubaidur Rob, Laila Rahman, A.K.M. Zafar Ullah Khan, Riad Mahmud, Azizul Alim, Ismat Ara Hena, Farhana Akter, and Anup Kumar Dey 
INCENTIVIZING PROVIDERS TO IMPROVE MATERNAL, NEWBORN AND CHILD HEALTH SERVICES IN BANGLADESH

TECHNICAL REPORT

\section{PAY-FOR-PERFORMANCE MODEL REFINEMENT AND ADVOCACY (P4P MRA) FINAL REPORT}

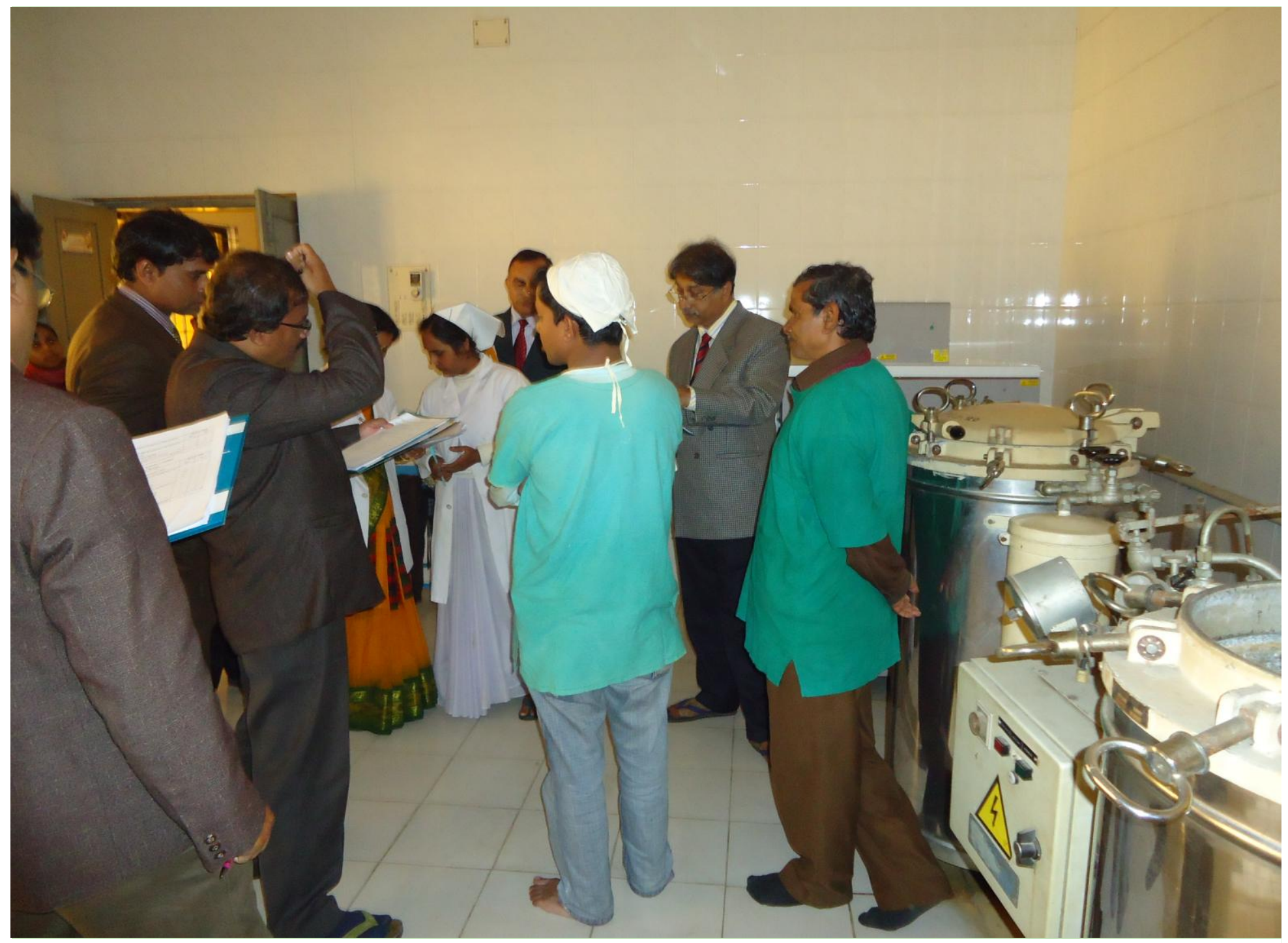

unicef

(2) Population Council 


\section{INCENTIVIZING PROVIDERS TO IMPROVE MATERNAL, NEWBORN AND CHILD HEALTH SERVICES IN BANGLADESH}

\section{PAY-FOR-PERFORMANCE MODEL REFINEMENT AND ADVOCACY (P4P MRA) FINAL REPORT}

Md. Noorunnabi Talukder ${ }^{1}$, Ubaidur Rob ${ }^{1}$, Laila Rahman ${ }^{1}$, A.K.M. Zafar Ullah Khan ${ }^{1}$, Riad Mahmud ${ }^{2}$, Azizul Alim ${ }^{3}$, Ismat Ara Hena', Farhana Akter ${ }^{1}$, and Anup Kumar Dey ${ }^{1}$

\footnotetext{
${ }^{1}$ Population Council, Bangladesh

${ }^{2}$ United Nations Children's Fund, Bangladesh

${ }^{3}$ Directorate General of Health Services, Ministry of Health and Family Welfare, Government of Bangladesh
}

Funding. United Nations Children's Fund (UNICEF) funded the P4P MRA project under the project cooperative agreement number UNICEF/PCA/2012/015, with funding from the Australian Agency for International Aid (AusAID), Canadian International Development Agency (CIDA), the United Kingdom's Department for International Development (DfID), and European Union (EU). The views expressed herein are those of the authors, and do not necessarily reflect the views of the Government of Bangladesh, Population Council, UNICEF, AusAID, CIDA, the United Kingdom's DfID, and EU. 


\title{
(2) Population Council
}

The Population Council confronts critical health and development issues-from stopping the spread of HIV to improving reproductive health and ensuring that young people lead full and productive lives. Through biomedical, social science, and public health research in 50 countries, we work with our partners to deliver solutions that lead to more effective policies, programs, and technologies that improve lives around the world. Established in 1952 and headquartered in New York, the Council is a nongovernmental, nonprofit organization governed by an international board of trustees.

Population Council Bangladesh Office House CES (B) 21, Road 118, Gulshan, Dhaka 1212, Bangladesh

Email: info.bangladesh@popcouncil.org

www.popcouncil.org

\section{unicef}

The United Nations Children's Fund (UNICEF) is the world's leading organization focusing on children and child rights. Established in 1946, UNICEF is active in 190 countries and territories through country programmes and National Committees. Headquartered in New York, UNICEF upholds the Convention on the Rights of the Child, and works to assure equality for those who are discriminated against, girls and women in particular. UNICEF works for the Millennium Development Goals and for the progress promised in the United Nations Charter. Striving for peace and security, UNICEF works to hold everyone accountable to the promises made for children.

\author{
UNICEF Bangladesh \\ BSL Office Complex \\ 1 Minto Road, Ramna, Dhaka 1000, Bangladesh \\ Email: dhaka@unicef.org
}

www.unicef.org.bd

Suggested citation: Md. Noorunnabi Talukder, Ubaidur Rob, Laila Rahman, A.K.M. Zafar Ullah Khan, Riad Mahmud, Azizul Alim, Ismat Ara Hena, Farhana Akter, and Anup Kumar Dey. 2012. "Incentivizing Providers to Improve Maternal, Newborn and Child Health Services in Bangladesh: P4P MRA Final Report.” Dhaka: Population Council.

Permission for reprint. Any part of this publication may be photocopied without permission from the publisher provided that copies are distributed without charge and that full source citation is provided. The Population Council would appreciate receiving a copy of any materials in which the text is used.

() 2012. The Population Council, Inc. 


\section{EXECUTIVE SUMIMARY}

\section{BACKGROUND}

From 2010 to 2011, an operations research (OR) project was conducted by the Directorate General of Health Services (DGHS) of the Ministry of Health and Family Welfare (MOHFW), Government of Bangladesh (GOB), with technical assistance from the Population Council (the Council) and the United Nations Children's Fund (UNICEF). The project tested the feasibility of a pay-for-performance (P4P) approach, which offered financial incentives to reward service providers for meeting and exceeding specified performance targets for maternal, newborn and child health (MNCH) services. In response to the encouraging findings that awarding incentives to providers increases the service volume and improves the quality of care, the DGHS implemented a follow-on project titled "P4P Model Refinement and Advocacy (P4P MRA)", with technical assistance from Population Council and UNICEF, to utilize the experiences and findings of the P4P OR project.

\section{OBJECTIVES}

The key objective of the P4P MRA project was to refine and utilize the institution-based incentivized service delivery model tested under the P4P OR project for increasing utilization of maternal, neonatal, and under-five children's health care services from public-sector facilities.

\section{DURATION}

The project was started in mid-February 2012 and ended in mid-August 2012, with the interventions being carried out for three months (March-May 2012).

\section{STUDY SITES}

The P4P MRA project implemented a refined P4P model in 12 health facilities of Gaibandha, Kurigram and Jamalpur districts that had participated in the P4P OR project. Intervention health facilities included three District Hospitals and nine Upazila Health Complexes (UHCs). Three facilities of Thakurgaon district (District Hospital and two UHCs) served as the comparison sites.

\section{ACTIVITIES}

\section{IMPLEMENTING A REFINED P4P MODEL}

Similar to the P4P OR project, the P4P MRA project provided conditional financial incentives to the $\mathrm{MNCH}$ team of a health facility for achieving predetermined performance targets. The MNCH team consists of managers, direct and indirect service providers and administrative and support staff of a facility, since the incentive scheme is designed to motivate all service providers within an institution. Financial incentives were provided to the institution for achieving quantitative and qualitative targets, on a quarterly basis. In addition to continuing the platform established by the P4P OR project, the P4P MRA project introduced three changes to the exiting interventions. 
- Intervention design. The modified P4P scheme under the P4P MRA project employed only performance incentives for motivating service providers to improve the quantity as well as the quality of services. Discontinuation of the demand-side financing for poor clients implemented under the P4P OR project was a major refinement.

- Quality assessment. In the P4P OR project, a Quality Assurance Group (QAG), an external body with an obstetrician, an anesthesiologist and a pediatrician from a higher-level facility, was formed to measure facility performance every three months by using paper-based monitoring tools with standard indicators. QAG assessments were used in calculating performance measurements for payment of incentives. The P4P MRA project introduced automated web-based QAG tools replacing the paper-based QAG checklists, which allow instant calculation of the quality of care $(\mathrm{QOC})$ scores and provide the reports to program managers, implementers, and service providers. Additionally, the P4P MRA project included QAG visits for the comparison facilities.

- Internal quality assurance. The P4P OR project formed Quality Assurance Teams (QATs), for each of the service units of the facility to monitor and review service performance monthly with a visual tool, to identify deficiencies and problems in service delivery and take measures accordingly, and to ensure coordination between team members, to improve internal quality and management. QATs have been continued in the P4P MRA project, with weekly review meetings replacing the monthly meetings.

\section{EVALUATION}

Regular service statistics were collected from the 15 facilities. In addition, 510 client exit interviews, 345 structured interviews with providers (including managers, doctors and nurses), 84 in-depth interviews with clients and providers, and 94 death reviews were carried out.

\section{RESULTS}

Changes in the volume of $\mathrm{MNCH}$ services. The P4P MRA project inherited an increased level of service volume contributed by the intervention of the P4P OR project over 14 months. The P4P MRA project was implemented for three months, yet some noticeable changes in the utilization of maternal health services occurred. A comparison of the quarterly average of institutional deliveries under the P4P OR project and the quarterly average for the P4P MRA project shows that the intervention facilities increased their performance on deliveries by 28 percent while the comparison facilities increased their performance by 14 percent. Differences in the improvement between the intervention and control facilities for PNC utilization are even greater. Comparison of ANC services indicates no considerable difference between intervention and control facilities.

Changes in the quality of MNCH services. The P4P MRA intervention facilities initially had higher QOC score compared to the comparison facilities (77 percent vs. 60 percent); following the single quarter intervention, this increased to 90 percent, which is significantly higher than the comparison facilities (64 percent).

Client satisfaction. A comparison of composite quality score on client satisfaction across the facilities reveals a higher reported satisfaction with maternal health services at the intervention facilities than at the comparison facilities. While the satisfaction scores for delivery services show a modest difference between intervention and comparison sites (78 percent vs. 74 percent), higher differences in the level of satisfaction were reported for ANC services between intervention and comparison (63 percent vs. 45 percent) and for PNC services (56 percent and 37 percent). 
Provider motivation. Provider motivation is measured in terms of supervision, teamwork and recognition. Providers in the intervention districts are twice as likely to receive periodic supervisory visits from higher-level facility as the control district (87 percent vs. 49 percent). The perception of the benefits of teamwork in ensuring appropriate distribution of responsibilities among staff members as well as improving quality of care is extremely low in control facilities (6 percent), compared with half of the providers in intervention facilities. Regardless of the exposure to interventions, providers echoed the necessity of financial incentives for working in rural areas, which was more pronounced at the intervention sites (97 percent). Approximately half of the providers expected recognition for their performance in the form of training.

Gaps in service delivery. During the three-month intervention period, 92 newborns and 2 women died at the facilities in two districts; these were systematically reviewed to determine the supply-side limitations contributing to these deaths. Labor attended by unskilled providers and poor skills of providers in recognizing a life-threatening condition or an emergency when births occur at home were the key causes of neonatal deaths. A small proportion of deaths ( 6 percent) occurred due to inadequate service provision at the facility, due to a lack of technology necessary to provide critical care, unavailability of a pediatrician, or providers not fully complying with treatment procedures.

The review of two maternal deaths identified the inadequate care in the community and upon arrival at the facility as the key causes of deaths. Supply-side factors responsible for these deaths include lack of inputs, e.g., blood transfusion, unavailability of essential obstetric care (EOC) trained doctor at receiving facilities, and lack of skills among community-level providers to identify high-risk mothers.

\section{COST OF SERVICES}

The cost per maternal health service unit (including antenatal, delivery and postnatal care services) incurred for the P4P MRA project was US\$5, which is lower than that incurred for the P4P OR project (US\$8). Provider incentive costs incurred for each delivery under the P4P MRA project was US\$33, remarkably lower than the P4P OR project (US\$58) and much lower than the government's DemandSide Financing (DSF) program (US\$70).

\section{CHALLENGES}

A six-month project with three-months of intervention was insufficient to carry out advocacy activities for sensitizing policymakers for scaling up and adopting the lessons learned. A joint GOB-UNICEFCouncil visit at a P4P MRA project site was carried out at the end of the project (in July 2012), but there was inadequate time to embark on a process to scale up the initiative, including national level advocacy. The brief project period also prevented a population-based evaluation.

\section{LESSONS LEARNED}

Despite it short duration, implementation of the revised P4P scheme induced improvements in service volume and quality of care. However, the P4P model, that rewards a team of providers for achieving performance targets, generated dissatisfaction among the providers when nonperformance by one unit affected the target achievement of the whole institution, thereby preventing the performing units from receiving their reward. 
Improvement in quality of services at the intervention facilities has been mainly due to the QAG and QAT innovations. Implementation of a system of regular performance review and reporting through unit-based QATs within the facility, and the performance assessment and mentoring by the external QAG contributed to quality improvement. Administration of the QAT monitoring tools within all service units was useful, as these tools assess the readiness and requirements of a unit, expediting decision-making. For the QAG, absence of outcome indicators in measuring quality of care remains a key deficiency.

Ensuring critical supply-side inputs, like the availability of qualified providers (e.g., EOC-trained doctor and pediatrician) at the facilities and the technology or services necessary to provide critical care (e.g., comprehensive EOC service with blood transfusion), is likely to reduce occurrence of maternal and newborn deaths. At the same time, developing skills among community-level providers to identify high-risk mothers is critical.

\section{NEXT STEPS}

Contribution of P4P interventions in rapidly raising the level and quality of institutional deliveries could strengthen the Government of Bangladesh efforts towards meeting the MDGs of reducing maternal and infant mortality, from two perspectives. First, the initiative should be continued until it significantly increases the number of institutional deliveries. Second, continuing incentives for service providers cannot be refuted unless alternative motivation is in place for the providers serving in rural areas.

An evaluation of implementation of a refined P4P model to measure changes in health outcomes at the population level and to compare costs between the P4P and DSF financing models would enable policymakers to make decisions on modification and scaling up of P4P and DSF models at the national level. Alternatively, DSF program could incorporate the QOC framework tested in the P4P project and replace the individual incentives for providers with an institution-based incentive approach. 


\section{TABLE OF CONTENTS}

Executive Summary

Table of Contents

vii

List of Tables

viii

List of Figures

viii

Abbreviations

ix

Acknowledgments

$x$

Background

1

Overview of the P4P Model

Objectives

Activities

Evaluation 10

Results 13

Advocacy 30

Implementation Challenges 31

Discussions 31

Lessons Learned 35

Next Steps 37

References

Appendix 


\section{LIST OF TABLES}

Table 1. List of Quality Assurance Teams across type of facilities

Table 2. Data collection according to district during March to May 2012

Table 3. Facility-based MPDR tools used for death reviews

Table 4. Changes in institutional delivery service volume by facilities

Table 5. Client's opinion on quality of care in receiving delivery services across arms (in percent)

Table 6. Advantages and challenges faced in the facilities, as reported by in-depth interview respondents across arms (in number)

Table 7. Improvements in service delivery and sustainability measures as reported by providers

Table 8. Provider supervision, teamwork and motivation across intervention and control sites (in percent)

Table 9. Review of newborn and maternal deaths occurred at facilities in Gaibandha and Kurigram (in numbers)

Table 10. Level of incentive achieved by intervention facilities

Table 11. Maternal services delivered and incentive cost per maternal service unit across intervention sites

\section{LIST OF FIGURES}

Figure 1. Quality of care score achieved by the study facilities in June 2012

Figure 2. Distribution of liquidated expenses by intervention facilities and head of expenditures

Figure 3. Provider incentive cost per delivery among P4P OR, P4P MRA and DSF (in US\$) 


\section{ABBREVIATIONS}

\begin{tabular}{|c|c|}
\hline ANC & Antenatal care \\
\hline AusAID & Australian Agency for International Development \\
\hline BMA & Bangladesh Medical Association \\
\hline CIDA & Canadian International Development Agency \\
\hline CIPRB & Center for Injury Prevention and Research Bangladesh \\
\hline Council & Population Council, Bangladesh \\
\hline CS & Civil Surgeon \\
\hline DfID & Department for International Development \\
\hline DGFP & Directorate General of Family Planning \\
\hline DGHS & Directorate General of Health Services \\
\hline $\mathrm{DH}$ & District Hospital \\
\hline DSF & Demand-side Financing \\
\hline EmONC & Emergency Obstetric and Newborn Care \\
\hline EOC & Essential Obstetric Care \\
\hline EU & European Union \\
\hline GOB & Government of Bangladesh \\
\hline MDG & Millennium Development Goal \\
\hline MIS & Management Information System \\
\hline MMR & Maternal Mortality Ratio \\
\hline $\mathrm{MNCH}$ & Maternal, Newborn and Child Health \\
\hline $\mathrm{MNH}$ & Maternal and Newborn Health \\
\hline MOHFW & Ministry of Health and Family Welfare \\
\hline MPDR & Maternal and Perinatal Death Review \\
\hline NGO & Non-governmental Organization \\
\hline OGSB & Obstetrical and Gynecological Society of Bangladesh \\
\hline $\mathrm{P} 4 \mathrm{P}$ & Pay-for-Performance \\
\hline P4P OR & P4P Operations Research \\
\hline P4P MRA & P4P Model Refinement and Advocacy \\
\hline PNC & Postnatal Care \\
\hline QAG & Quality Assurance Group \\
\hline QAT & Quality Assurance Team \\
\hline QOC & Quality of Care \\
\hline RMO & Resident Medical Officer \\
\hline SPSS & Statistical Package for Social Science \\
\hline $\mathrm{UHC}$ & Upazila Health Complex \\
\hline UHFPO & Upazila Health and Family Planning Officer \\
\hline UN & United Nations \\
\hline UNICEF & United Nations Children's Fund \\
\hline
\end{tabular}




\section{ACKNOWLEDGMENTS}

Population Council collaborated with the Government of Bangladesh and United Nations Children's Fund (UNICEF) to implement the P4P Model Refinement and Advocacy (P4P MRA) project, a follow-on initiative of the P4P operations research study that tested an innovative pay-for-performance scheme to improve maternal, newborn and child health in Bangladesh in order to contribute to the Millennium Development Goals 4 and 5. The Final Report of the P4P MRA project gives overview of the study activities, reveals results, and discusses implications of the study for Bangladesh.

The authors are grateful to Mr. Md. Humayun Kabir, Senior Secretary, Ministry of Health and Family Welfare, and Professor Dr. Khondhaker Md. Shefyetullah, Director General, Directorate General of Health Services (DGHS) of the Government of Bangladesh for their overall guidance to the study. We sincerely thank Dr. Abu Jafar Md. Musa, Director, Primary Health Care and Line Director, Maternal, Newborn, Child and Adolescent Health, DGHS for his insights towards developing the future course of action.

Civil Surgeons, Deputy Directors Family Planning, and Presidents of the Bangladesh Medical Associations of Gaibandha, Kurigram, Jamalpur and Thakurgaon districts as well as the Upazila Health and Family Planning Officers, Resident Medical Officers, Consultants, doctors, and all the MNCH providers and staff of the four District Hospitals, and eleven Upazila Health Complexes, namely, Sunderganj, Shaghata, Fulchari, Nageswari, Bhurungamari, Chilmari, Islampur, Melandah, Bakshiganj, Pirganj and Ranisankoil, are acknowledged for extending their cooperation and inputs during project implementation. Quality Assurance Group members from Mymensingh and Rangpur Medical Colleges, Obstetrical and Gynecological Society of Bangladesh as well as District Hospitals and Upazila Health Complexes deserve special thanks.

We are immensely grateful to Dr. John Townsend, Vice President, Reproductive Health Program, Population Council, Dr. Ian Askew, Director, Reproductive Health Services and Research, Population Council, and Joanne Gleason, Associate Director, Population Council for their professional input for reviewing the report. All the P4P MRA project staff members of the Council deserve special thanks for their excellent contribution.

We acknowledge the Australian Agency for International Development, Canadian International Development Agency, the United Kingdom's Department for International Development, and European Union for funding this important research endeavor through UNICEF. 
From 2010 to 2011, an operations research was conducted by the Directorate General of Health Services (DGHS) of the Ministry of Health and Family Welfare (MOHFW), Government of Bangladesh (GOB), with technical assistance from the Population Council (the Council) and the United Nations Children's Fund (UNICEF) to test the feasibility of pay-for-performance (P4P) approach, which offered financial incentive to reward service providers for meeting certain performance targets on maternal, newborn and child health ( $\mathrm{MNCH}$ ) services. Two intervention arms or strategies were employed for 14 months in 12 public-sector health facilities of three districts where the 'first arm' was a combination of the pay-for-performance for providers and demand-side-financing for poor clients while the 'second arm' employed only the pay-for-performance incentive for providers. Three facilities from another district comprised the control arm.

Under the P4P operations research (OR) project, a financial incentive was provided to the team consisting of managers, direct and indirect providers, and administrative and support staff of a health facility for achieving or exceeding quantitative and qualitative targets. Quarterly targets (both quantitative and qualitative) for maternal, newborn and child health services were set for the institution as a whole. An external body, comprising of an obstetrician, an anesthesiologist and a pediatrician from a higher-level facility, measured the facility performance every three months by using monitoring tools with standard indicators. The effectiveness of performance incentives was measured in terms of increased volume of services and improvement in quality of care. Comparison across strategies and comparison sites indicates that payment for providers, with or without financing for clients, results in increased utilization of $\mathrm{MNCH}$ services. Institutional deliveries increased by 114 and 32 percent in facilities under strategies I and II, respectively, relative to 8 percent increase in comparison facilities (Rahman et al. 2011). Overall, due to P4P interventions, service volume increased remarkably, where each District Hospital doubled the performance in institutional delivery while each Upazila Health Complex tripled that performance (Talukder et al. 2011). Simultaneously, the intervention facilities succeeded in improving quality of services, with an increase in quality score from 54 percent before intervention to 77 percent during intervention (Rahman et al. 2011).

In response to the encouraging findings that awarding incentives to providers increases the service volume and improves the quality of care, the DGHS implemented a six-month P4P follow-on project titled "Pay-for-Performance to Increase Utilization of Maternal, Newborn and Child Health Services in Bangladesh: Model Refinement and Advocacy (P4P MRA)" in order to ensure utilization of the experiences and findings of the P4P OR project. Population Council and UNICEF provided technical assistance to the DGHS to implement a refined P4P model with a modified quality measurement tool. This follow-on project was also intended to carry out advocacy to utilize the research findings among the stakeholders.

Similar to the P4P OR project, the P4P MRA project is nested within the GOB-UN MNCH and Maternal and Newborn Health (MNH) projects to enable the GOB to improve performance, through human resource incentives tied to target achievement of $\mathrm{MNCH}$ services, and refine the model for wider 
utilization in the country. BRAC, CARE and partner non-governmental organizations (NGOs) of $\mathrm{MNCH} / \mathrm{MNH}$ project and Rangpur and Mymensingh Medical Colleges remain as partners. Professional bodies including the Obstetric and Gynecological Society of Bangladesh (OGSB) and Bangladesh Medical Association (BMA), elected local government representatives, and community members are the extended partners of the facilities. The project is supported by the Australian Agency for International Aid (AusAID), Canadian International Development Agency (CIDA), the United Kingdom's Department for International Development (DfID), and European Union (EU). Like the P4P OR project, the P4P MRA project aims to improve the $\mathrm{MNCH}$ service delivery in order to increase the utilization of maternal, neonatal and under five children's health services.

\section{CONTEXT}

\section{MATERNAL, NEWBORN AND UNDER FIVE CHILDREN'S HEALTH CARE SITUATION}

Bangladesh has made tremendous gains in reducing the maternal mortality ratio (MMR) from 650 in 1989 to 194 per 100,000 live births in 2010 (NIPORT, Measure Evaluation, and ICDDR,B 2011). The country needs to reduce MMR further, to 143 by 2015, to achieve the Millennium Development Goal (MDG) 5. Notwithstanding the significant progress made in the past two decades in improving maternal health, reducing the inequity in utilization of maternal health services between urban and rural areas remains the key challenge. Home is still the site of 77 percent of deliveries (urban $62 \%$ versus rural $80 \%$ ), where traditional birth attendants with little knowledge and skills are primary service providers (NIPORT, Measure Evaluation, and ICDDR,B 2011). Although 54 percent (urban $68 \%$ versus rural $49 \%$ ) of pregnant women receive antenatal care (ANC) from medically trained providers, only one in four women attain the four recommended ANC visits (NIPORT, Measure Evaluation, and ICDDR,B 2011). Utilization of postnatal care (PNC) is even worse, with only 23 percent of women receiving PNC within 48 hours of delivery from any medically trained provider, again with high inequalities (urban $37 \%$ versus rural 18\%) (NIPORT, Measure Evaluation, and ICDDR,B 2011). Infant postnatal checkup utilization is nearly similar to women's PNC. Only 30 percent of infants receive a check-up from medical provider within two days of birth, with wide disparities between urban and rural areas (NIPORT, Mitra and Associates, and ICF International 2013). Findings suggest alarmingly low use of child health care in Bangladesh. Only one in four children with diarrheal diseases, and one in three infants with symptoms of acute respiratory infections are taken to a health facility or medically trained health provider, respectively (NIPORT, Mitra and Associates, and ICF International 2013). The key challenges to reducing maternal, neonatal and under-five child mortality include lack of access and inadequate and poor quality of $\mathrm{MNCH}$ services.

\section{CHALLENGES TO MNCH SERVICE DELIVERY IN RURAL AREAS}

Although the government has developed a comprehensive $\mathrm{MNCH}$ service delivery infrastructure from grassroots to higher levels, there is significant underutilization of existing capacity. In rural areas, health facilities at the sub-district level and below operate at less than their capacity due to shortage and sub-optimal performance of service providers (Talukder and Rob 2009), and dysfunctional 
incentive environment in the health system (UNICEF 2008). Unavailability of services at government facilities is partly responsible for low utilization of maternal health services. Evidence suggests that less than 20 percent of health facilities at the sub-district level are adequately staffed to provide emergency obstetric care (Chowdhury et al. 2009). Further, low quality services provided at facilities reduce demand for $\mathrm{MNCH}$ services (Rahman et al. 2011).

Bangladesh is one of the few countries in which physicians far exceed nurses and trained midwives (BHW 2008), but most physicians are concentrated in urban areas, as rural sites do not offer urban amenities and have limited scope for private practice. Shortages in skilled health workers are results of weak incentives and low remuneration for public-sector service providers (UNICEF 2008). The payment system in the public sector does not offer performance incentives to health service providers. Moreover, the remuneration of these service providers is well below than that of the private sector. Therefore, public-sector providers remain absent; and tend to refer patients to their own private clinics for personal gain, or alternatively, they charge unofficial fees when services at government facilities are supposed to be free or very low cost. This situation increases the poor's out-of-pocket cost and makes obtaining necessary services difficult (Rob, Talukder and Ghafur 2006). Poor supervision and monitoring systems and absence of financial incentives discourage providers to be accountable and responsive to the patients. These factors indicate that service providers can be motivated by financial gain tied with performance targets.

\section{OVERVIEW OF THE P4P MODEL}

The P4P OR project tested the effectiveness of introducing performance-based incentives to increase the utilization of maternal, newborn and child health services. Performance-based incentive was implemented in 12 public-sector health facilities of three districts. From each district, one District Hospital and three Upazila Health Complexes (UHCs) received the interventions. P4P OR examined the feasibility of both supply- and demand-side incentives. At the supply side, a conditional financial incentive was provided to the facility for motivating service providers to improve quantity as well as quality of services. Other supply-side interventions included promoting teamwork, introducing quality assurance, and strengthening referral system. At the demand side, financial assistance was provided to poor clients in an attempt to subsidize their out-of-pocket costs to receive services. This intervention of the P4P OR project has not been continued in the follow-on P4P MRA project. The follow-on project (P4P MRA) implemented only the supply-side interventions. The duration of interventions was five quarters for P4P OR while it was only one quarter for P4P MRA.

\section{P4P INNOVATIONS}

\section{PROMOTING TEAMWORK}

Quality of care and utilization of MNCH services depend on well-coordinated teams at the health facility. P4P is a pioneer project in Bangladesh where incentive is provided to the institution in order to strengthen $\mathrm{MNCH}$ services of a facility, with team work being a prerequisite. The maternal, newborn and child health team is aligned consisting of managers, direct and indirect service 
providers and administrative and support staff of a facility since the incentive scheme is designed to motivate service providers at the institution level.

Within the facility, the $\mathrm{MNCH}$ team is divided into smaller teams or service units to provide specific services with the leadership mechanism at both facility and service unit levels. Quality Assurance Teams (QATs) are formed for the following units: emergency room, labor room, operation theater, autoclave room, female ward, child ward or newborn care corner, pharmacy, store, laboratory, antenatal and postnatal care corner, and family planning corner. For each of the QATs, a leader is nominated and given responsibility to coordinate the activities of the respective unit. They monitor and review service performance routinely with visual QAT tool ${ }^{1}$, identify deficiency and problems in service delivery and take measures accordingly, and ensure coordination between team members.

\section{INTRODUCING QUALITY ASSURANCE}

Establishing a quality assurance system is one of the key prerequisites for introducing P4P approach. Individual Quality Assurance Group (QAG) has been formed for each of the study facilities, consisting of specialists from nearby higher-level hospital (e.g., medical college) and professional body, with two broad purposes: accredit the facilities that provide minimum acceptable level of MNCH care, and ensure routine assessment of performance of the facility. During quarterly visit to the facility, QAG members-obstetricians, pediatricians and anesthetists-review performance and grade the facility, identify gaps in service delivery, and measure performance of QAT members and mentor them towards ensuring quality in services. QAG assessments are used in calculating performance measurement for payment of incentive.

\section{INTRODUCING P4P APPROACH}

Conditional financial incentive is provided to motivate service providers at the institution level, where provider performance is linked with both quantity and quality of services. The main thrust of introducing P4P approach is to increase institutional deliveries, where managers, direct and indirect providers related to $\mathrm{MNCH}$ services, and administrative and support staff receive incentive if the facility achieves or exceeds performance targets. For the P4P OR project, the incentive scheme was in effect from October 2010 through November 2011; and for the P4P MRA project it was from March to May 2012.

- Performance targets. The incentive was paid on quarterly basis. Quarterly targets for $\mathrm{MNCH}$ services are set for the institution as a whole, which takes into account both quantity and quality of services. Two levels of quantitative performance targets based on the benchmark are set to pay incentives to a health facility. The initial benchmark is based on the individual facility's past year's performance. Targets are set for antenatal care, safe institutional delivery, postnatal care services, and family planning counseling.

Qualitative targets are set for the relevant MNCH service units or QATs. A weighted score on a one-hundred point scale is used to measure the performance in terms of quality of care.

${ }^{1}$ QAT tool, consisting of a list of requisite equipments, drugs and supplies for a service unit, describes the readiness and requirements of a unit. 
The indicators for which facility cannot be held entirely responsible have less weight while the important $\mathrm{MNCH}$ indicators for which the facility can be held responsible have higher weight. For instance, human resource availability related indicators hold weight 0.5 while the signal functions on managing emergency obstetric and newborn care (EmONC) complications for pregnant women and newborn have weight 2. The total weighted scores of all the MNCH service units are transformed into a 100-point scale for comparison with the previous quarter. Two levels of predetermined targets are used to assess the overall quality of the facility.

- Performance measurement. At the end of the quarter, the performance of a facility is measured using service statistics and quality assessments by QAG, and hence, the eligibility of the facility for incentive is determined. QAGs visit the facilities to measure the quality of care following an agreed upon checklist. Upon reviewing the facility's performance, the QAG recommends either rewarding the facility with incentives or not recommending any incentive due to a lack of improvement in performance. If a facility achieves both the volume and quality targets, then they become eligible to receive performance incentives.

Achieving only the quantitative target does not make a facility eligible to receive the incentive. For the first level of incentive, the facility must meet the first level of qualitative target along with at least the first level of the quantitative target; and for the second level of incentive, facilities must meet the second level targets for both qualitative and quantitative measures.

- Levels of incentive. The amount of incentive for a facility varies according to its level of performance improvement. The first level of incentive amount for a quarter is equivalent to a person's one-month basic salary; and the second level of incentive equals one and a half month's basic salary of the respective providers. Incentives payable to providers and staff are calculated on the basis of level of efforts; for instance, managers and direct service providers receive a full incentive while indirect service providers and administrative staff receive half incentive, while for the support staff it is either 50 to 100 percent.

- Incentive payment. The Council reimburses incentive payments through a systematic financial mechanism established for calculating, disbursing and verifying incentives. A facility-based project implementing committee, commonly known as P4P Committee, receives an advance payment from the Council to pay incentives to the providers by bank transfers. An audit firm, engaged by the Council, validates the payment made to the providers and service volume reported by the facilities and cross-checks the exposure of clients to the interventions.

\section{STRENGTHENING REFERRAL SYSTEM}

Referral system has been strengthened through ensuring coordination among three types of fieldworkers (i.e., Health Assistants, Family Welfare Assistants and NGO fieldworkers) and providing referral incentive. Incentives are given to fieldworkers for referring appropriate cases to intervention facilities. 


\section{KEY IMPLEMENTERS OF THE INITIATIVE}

The key implementers of the provider incentive payment model include the DGHS as the regulator, the facility $\mathrm{MNCH}$ team as the providers, Population Council as the payment administrator, an external body consisting of specialist doctors to measure performance in terms of quality of care, and an independent audit firm to validate service volume reported by the facilities.

\section{BENEFICIARIES}

Health facility managers, direct and indirect MNCH providers, and administrative and support staff of the 12 intervention facilities are the primary beneficiaries while the pregnant women, newborns, and under-five children, with increased accessibility to, availability of, and use of quality $\mathrm{MNCH}$ care services, are the secondary beneficiaries of the project. At the policy level, information on the P4P model and tools will be immensely useful to government and non-government policymakers and program managers to understand, discuss, and bring changes into the existing $\mathrm{MNCH}$ practices.

\section{OBJECTIVES}

The key objective of the P4P MRA project is to refine and utilize the institution-based incentivized service delivery model tested in the P4P OR project for increasing utilization of maternal, neonatal, and under-five children's health care services from public-sector health facilities. The project is expected to contribute to achieving the MDG targets 4 and 5 and inform improving the health system financing approaches in Bangladesh. 


\section{ACTIVITIES}

\section{IMPLEMENTATION OF THE REFINED P4P MODEL DURING MARCH TO MAY 2012}

\section{STUDY SITES}

The 15 health facilities of Gaibandha, Kurigram, Jamalpur and Thakurgaon districts are the study sites of the P4P MRA project, which are continued for being the P4P OR project sites. Health facilities include four District Hospitals of Gaibandha, Kurigram, Jamalpur and Thakurgaon districts, and eleven Upazila Health Complexes including Sundarganj, Shaghata and Fulchari UHCs of Gaibandha, Nageswari, Bhurungamari and Chilmari UHCs of Kurigram, Islampur, Melandah and Bakshiganj UHCs of Jamalpur, and Ranishankail and Pirganj UHCs of Thakurgaon. Twelve health facilities of Gaibandha, Kurigram and Jamalpur districts are the intervention facilities, and three facilities of Thakurgaon district are the comparison sites.

\section{P4P MODEL REFINEMENT}

The major model refinement under the P4P MRA project is that single strategy was tested across all intervention sites. The modified P4P scheme under the P4P MRA project employed only the pay-forperformance incentive for motivating service providers to improve quantity and quality of services. Discontinuation of the demand-side financing for the poor clients implemented under the P4P OR project was a major refinement. The P4P MRA intervention was implemented only for three months; hence it was not possible to incorporate coupons for the poor MNCH clients, because at least an 18month period is required for the implementation of demand-side financing for pregnancy care using coupons.

\section{REFINING THE QUALITY ASSESSMENT PROCESS}

Team composition of the QAG members remains the same for both the P4P OR and P4P MRA projects; but three improvements have been made in the P4P MRA project: introduction of automated web-based QAG tools for recording and calculating quality score; the inclusion of comparison facilities for QAG visit; and introduction of specific quality targets.

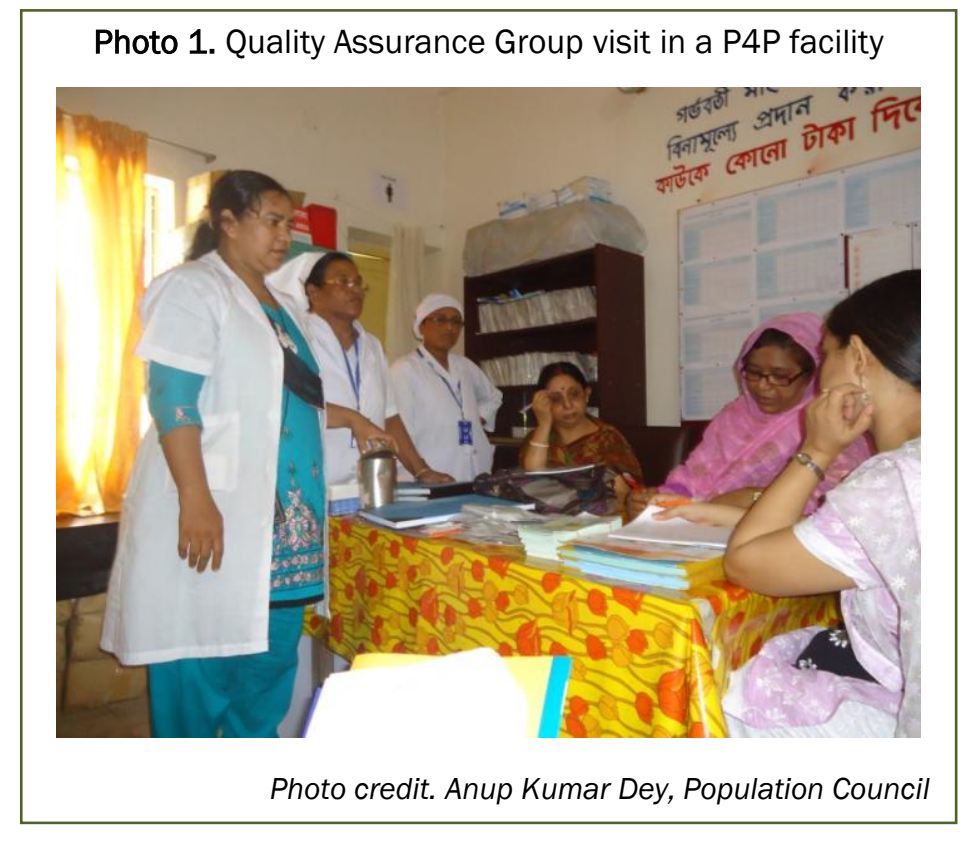


The P4P MRA project introduces automated web-based QAG tools replacing the paper-based QAG checklists used in the P4P OR project, which allows instant calculation of the quality of care (QOC) scores. In addition, this software generates reports highlighting the weak and strong points for each $\mathrm{MNCH}$ unit of service delivery allowing better management and scope for improvement. The software also gives online access to the QAG visit reports to the program managers and implementers and study facilities.

Comparison facilities did not undergo the QAG assessment process during the implementation of 14-month P4P OR project. Under the P4P MRA project, both the intervention and comparison facilities received QAG visits.

Qualitative targets are set for the facility before the performance quarter begins. Total weighted scores of all the MNCH service units are transformed into a 100point scale. First level of qualitative target has been set at

Photo 2. Quality assurance measurement software log-in page

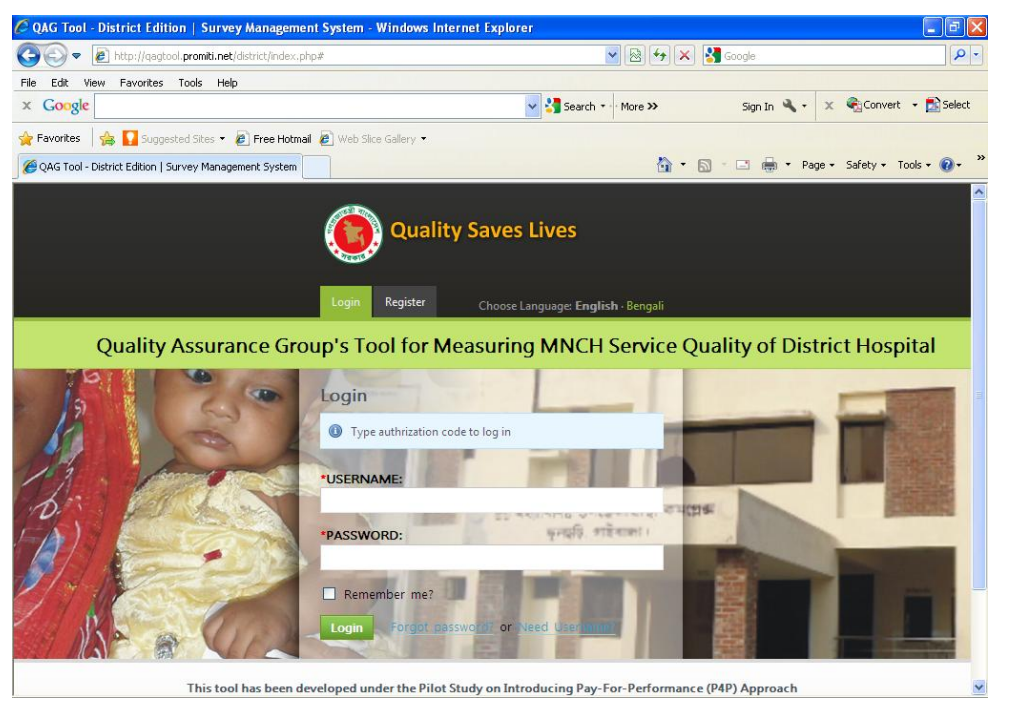
the QOC score of 67 out of 100 and the second level qualitative target at 85 out of 100 .

\section{USING P4P-COMMITTEE AND QAT MEETINGS FOR DECISION MAKING}

To lead and manage the project implementation activities, P4P Committees that were formed for the P4P OR project have been continued to the end of the P4P MRA project. P4P Committee for the District Hospital headed by Civil Surgeon (CS) includes Resident Medical Officer (RMO) as the member-secretary and Deputy Director of Family Planning, President of the local branch of BMA, an NGO representative and Nursing Supervisor as committee members. P4P Committee for the Upazila Health Complex is comprised of six members: Upazila Health and Family Planning Officer (UHFPO) as the president, RMO as the member-secretary, elected female local-government representative, Upazila Family Planning Officer, an NGO representative, and Nursing Supervisor. Twelve facilities of Gaibandha, Kurigram and Jamalpur districts held monthly meetings among the P4P Committee members for making improvement in service delivery and achieving the targets.

QATs, that were formed under the P4P OR project for different service units within the facility to enable the institution to ensure their quality of care, have been continued in the P4P MRA projectan important innovation to improve and sustain the facility performance. Monitoring tools in Bangla, describing the readiness and requirements of a unit, were posted on the wall to allow the QAT team leaders to monitor and record the performance of their respective units once a week. Civil Surgeon/UHFPO and RMO monitor the units at least once a month, and record their observations 
and suggestions on the tool. There have been regular weekly meetings among QAT members for making improvement in service delivery and achieving the targets.

Table 1. List of Quality Assurance Teams across type of facilities

\begin{tabular}{l|l|l}
\hline District Hospital & Comprehensive EmONC UHC & Basic EmONC UHC \\
\hline - Emergency room & - Emergency room & - Emergency room \\
- Autoclave/sterilization room & - Autoclave/sterilization room & - Autoclave/sterilization room \\
- Pharmacy & - Pharmacy & - Pharmacy \\
- Store & - Store & - Laboratory/pathology \\
- Laboratory/pathology & - Laboratory/pathology & - Labor room \\
- Labor room & - Labor room & - Obstetrics ward/ Female ward \\
- Obstetrics ward & - Obstetrics ward/ Female ward & - Antenatal care, postnatal care \\
- Antenatal care, postnatal & - Antenatal care, postnatal care & and family planning corner- \\
care and family planning & and family planning corner- & DGHS \\
- Porner & DGHS & Antenatal care, postnatal care \\
ward(s) & - Antenatal care, postnatal care & DGFP \\
- Operation theater & and family planning corner- & Femanning corner- \\
& DGFP & children) \\
\hline
\end{tabular}




\section{EVALUATION}

A six-month period was not adequate for the P4P MRA project (inclusive of three-month intervention period) to conduct a pre-post comparison by using population-based surveys. Instead, comparisons restricted within the intervention period were made to measure the impact of the intervention between experimental and control groups. As part of the evaluation activities, regular service statistics were collected from 15 facilities during March to May 2012. In addition, 510 client exit interviews, 345 structured interviews with the providers including managers, doctors and nurses, 84 in-depth interviews with clients and providers, and 94 death reviews were carried out.

Table 2. Data collection according to district during March to May 2012

\begin{tabular}{lccccc}
\hline Districts & $\begin{array}{c}\text { Client exit } \\
\text { interviews }\end{array}$ & $\begin{array}{c}\text { Provider } \\
\text { survey }\end{array}$ & $\begin{array}{c}\text { In-depth } \\
\text { interviews with } \\
\text { clients }\end{array}$ & $\begin{array}{c}\text { In-depth } \\
\text { interviews with } \\
\text { providers }\end{array}$ & $\begin{array}{c}\text { Death } \\
\text { reviews* }\end{array}$ \\
\hline Gaibandha & 147 & 82 & 12 & 12 & 49 \\
Kurigram & 131 & 79 & 12 & 7 & 45 \\
Jamalpur & 133 & 116 & 12 & 9 & - \\
\hline $\begin{array}{l}\text { Total intervention } \\
\text { districts }\end{array}$ & 411 & 277 & 36 & 94 \\
\hline Thakurgaon & 99 & 68 & 11 & 37 & 94 \\
\hline Total & 510 & 345 & 47 & 9 & 9 \\
\hline
\end{tabular}

* Deaths occurred in Jamalpur and Thakurgaon districts not reviewed under the P4P MRA project

\section{FACILITY MIS}

The P4P MRA project used the same process for colleting and managing data as established by the P4P OR project. Management information system (MIS) data on monthly performance have been the key to the measurement of the quantitative targets pursued and achieved by the facilities, and for evaluating the $\mathrm{MNCH}$ service delivery in terms of quantity across facilities.

Facility-based MIS data have been collected from the 15 facilities for 8 months, from January 2012 to August 2012. Existing MIS administered by Health Directorate allows upazila and district level facilities to record aggregated monthly data on essential obstetric care (EOC) and integrated management of childhood illnesses (IMCl) related services. The current system is fraught with lapses as data are often not accessible because of manual collection and storage. Duplication in the collection of health and family planning data by two Directorates (Health and Family Planning) without any coordination for sharing these mutually useful data hinders measuring the actual performance of the facility. Considering these bottlenecks, MIS data have been extracted from the monthly reports and registers maintained at the facilities. Council researchers collected the information directly from the facilities in cooperation with the facility staff. Two data collectors per district were stationed for continuous and multiple data collection activities as a part of the 
evaluation team. Council's district-level coordinators monitored the data collection and data management specialist collated and checked quality of the data for consistency and accuracy. A form developed to record data on family planning counseling for the P4P OR project was also administered in the P4P MRA project.

\section{QAG VISITS}

QAGs made two visits at 15 facilities: one in March 2012 and the other in June 2012. QAG members administered web-based automated checklists appropriate for District Hospital, UHC providing comprehensive EmONC services and UHC providing basic EmONC services. Unlike the P4P OR project, QAG visits were made at the comparison sites under the P4P MRA project, which enabled to measure and compare quality of care across the intervention and control sites.

\section{PROVIDER SURVEY}

A total of 345 providers were interviewed during the intervention period from 15 facilities using a semi-structured questionnaire on motivation and problems faced in carrying out the MNCH services. Survey participants included managers and direct providers including consultants, doctors and nurses. Data have been entered and analyzed using the SPSS program.

\section{CLIENT EXIT INTERVIEWS}

Exit interviews were carried out with $510 \mathrm{MNCH}$ clients at 15 health facilities after receiving services during the intervention period (from March 2012 to May 2012). Clients visiting the facilities for six services, namely ANC check-up, delivery, PNC check-up, delivery complications management services, newborn complications management services, and under-five children's complications management services were interviewed with the purpose to ascertain their experiences and opinion on quality of services. Council researchers conducted the interviews and entered data into an MS Access software after cross-checking and editing. Data were entered twice to ensure the quality. Council's district-level coordinators monitored the data collection, and data management specialist collated and checked quality of data for consistency and accuracy. Exit client interview data have been analyzed using the SPSS program.

\section{IN-DEPTH INTERVIEWS WITH CLIENTS AND PROVIDERS}

In-depth interviews were carried out with 47 women who received $\mathrm{MNCH}$ services during the intervention period from 15 facilities to learn about the contextual factors as well as the benefits and challenges that they encountered in receiving care from the facilities. Similarly, 37 providers were interviewed in-depth to learn their opinion on the implementation of P4P approach and its sustainability. 


\section{DEATH REVIEWS}

Population Council with technical assistance from the Center for Injury Prevention and Research Bangladesh (CIPRB) implemented maternal and perinatal death review (MPDR) at eight intervention facilities of Gaibandha and Kurigram districts. To begin with, a workshop with managers and doctors of the intervention facilities was conducted to review the MPDR tool and training materials. A guideline was developed and approved by the DGHS. Nurses, doctors and facility managers were trained on using and analysis of tools to identify the gaps in services for which the death occurs. Following a three-step process, facilities carried out maternal and perinatal death review every month (Table 3).

Table 3. Facility-based MPDR tools used for death reviews

\begin{tabular}{|c|c|c|}
\hline Tool & Responsible person & Information to be obtained \\
\hline Death notification slip & Senior Staff Nurse/Nurse & $\begin{array}{l}\text { - Date and time of admission and } \\
\text { death } \\
\text { - Address of the deceased }\end{array}$ \\
\hline $\begin{array}{l}\text { Death review forms (maternal and } \\
\text { neonatal deaths and still birth) }\end{array}$ & Senior Staff Nurse/Nurse & $\begin{array}{l}\text { - Direct and indirect causes of death } \\
\text { - Description of treatment }\end{array}$ \\
\hline $\begin{array}{l}\text { Agreed Standard Procedure (ASP) } \\
\text { form (maternal and neonatal } \\
\text { deaths and still birth) }\end{array}$ & Doctor & $\begin{array}{l}\text { - Assess clinical quality of care, and } \\
\text { logistics support and management } \\
\text { - Identify the gaps of services and } \\
\text { needs }\end{array}$ \\
\hline
\end{tabular}




\section{RESULTS}

\section{CHANGES IN THE VOLUME OF MNCH SERVICES}

The P4P MRA project has inherited an increased level of service volume contributed by the fivequarter intervention of the P4P OR project. P4P MRA was implemented for a single quarter (three months) and had no opportunity to lift the service volume in case of an underperformance.

Nevertheless, this single quarter intervention brought some noticeable changes in the utilization of maternal health services.

Table 4. Changes in institutional delivery service volume by facilities

\begin{tabular}{|c|c|c|c|}
\hline Facilities & $\begin{array}{r}\text { Quarterly Average } \\
\text { October'10-November'11 }\end{array}$ & $\begin{array}{l}\text { Quarterly Average } \\
\text { March-May } 2012\end{array}$ & Percentage difference \\
\hline \multicolumn{4}{|l|}{ Intervention } \\
\hline Gaibandha DH & 174 & 260 & $49 \%$ \\
\hline Sundarganj UHC & 64 & 153 & $139 \%$ \\
\hline Saghata UHC & 45 & 93 & $106 \%$ \\
\hline Fulchari UHC & 28 & 50 & $79 \%$ \\
\hline Gaibandha District & 78 & 139 & $78 \%$ \\
\hline Kurigram DH & 235 & 329 & $40 \%$ \\
\hline Nageswari UHC & 81 & 52 & $-36 \%$ \\
\hline Bhurungamari UHC & 49 & 76 & $54 \%$ \\
\hline Chilmari UHC & 100 & 103 & $3 \%$ \\
\hline Kurigram District & 116 & 140 & $20 \%$ \\
\hline Jamalpur DH & 566 & 551 & $-3 \%$ \\
\hline Islampur UHC & 80 & 129 & $62 \%$ \\
\hline Melandah UHC & 38 & 73 & $90 \%$ \\
\hline Bakshiganj UHC & 104 & 140 & $35 \%$ \\
\hline Jamalpur District & 197 & 223 & $13 \%$ \\
\hline \multicolumn{4}{|l|}{ Comparison } \\
\hline Thakurgaon DH & 442 & 538 & $22 \%$ \\
\hline Pirganj UHC & 207 & 206 & $-1 \%$ \\
\hline Ranishankail UHC & 91 & 98 & $8 \%$ \\
\hline Thakurgaon District & 247 & 281 & $14 \%$ \\
\hline Intervention sties & 130 & 167 & $28 \%$ \\
\hline Comparison sites & 247 & 281 & $14 \%$ \\
\hline
\end{tabular}

$\mathrm{DH}=$ District Hospital

UHC= Upazila Health Complex 
Table 4 describes a comparison between the quarterly average of institutional delivery services under the P4P OR project (October 2010-November 2011) and the performance of institutional delivery services for single quarter intervention of the P4P MRA project (March-May 2012). Overall, the intervention facilities increased their performance by 28 percent while the comparison facilities increased their performance by 14 percent. Percentage differences over time between the intervention and the comparison facilities are significant $(p=0.02)$.

Despite the irrevocable risk associated with single quarter intervention, facilities of Gaibandha and Kurigram increased institutional deliveries relative to average P4P OR performance by 78 and 20 percent, respectively. There was lower increase in the service volume of institutional deliveries for Jamalpur and Thakurgaon, with a negligible difference between them. Out of 12 intervention facilities, 7 facilities made about 50 percent increase in institutional delivery within three months. Of them, three facilities - Sundarganj, Shaghata and Melandah - approximately doubled their performance in institutional delivery. The performance of Nageswari UHC declined; and Chilmari UHC and Jamalpur District Hospital could not bring any change (Table 4). The reason for Nageswari UHC's decline of performance of institutional delivery services lies in their inability to perform as a comprehensive EmONC facility due to unavailability of obstetrician and anesthesiologist pair, and infrastructure renovation activities.

Facilities of Gaibandha and Jamalpur districts increased their performance significantly in antenatal and postnatal care services, while no notable changes were observed in Kurigram and Thakurgaon districts. Increase in the service volume was greater for postnatal care than that of antenatal care. Volume of PNC services increased significantly by 46 percent in the intervention facilities relative to a minimal 10 percent increase at the comparison facilities (Appendix Table A1, A2). Modest increase in ANC services caused by three-month intervention can be due to the saturation engendered by incentive-induced higher rate of utilization of ANC services during the P4P OR project, leaving little scope for the intervention facilities to optimally increase service volume for ANC services.

It is worth noting that during the P4P OR study, among three intervention districts, Gaibandha and Kurigram provided a financial incentive to poor clients, which was discontinued in the P4P MRA project. Considering the discontinuation of financial assistance to the poor clients, the facilities of Kurigram kept their quantitative targets similar to the last year's target. This could be a reason for Kurigram not achieving higher service volume. In contrast, Gaibandha kept setting higher targets, and achieved higher service volumes in terms of ANC and PNC services.

\section{CHANGES IN THE QUALITY OF MNCH SERVICES}

Pre-invention QAG assessment conducted in March 2012 reveals that the average QOC score achieved by the 12 intervention facilities was 79 out of 100, which was well above the first level of quality score of 67 points, but only two facilities exceeded the second level of quality score of 85 out of 100. Ten facilities needed further improvement in order to achieve the second level of quality score. All three facilities of the control district (Thakurgaon District Hospital, Ranishankail and Pirganj UHCs) achieved a score of only 60 out of 100, which is well below minimum 67 required for the first level of QOC target (Figure 1). The comparison facilities did not undergo the QAG assessment 
process during the 14-month P4P OR project. Higher QOC score achieved by the intervention facilities (red line), therefore, could be due to the performance-induced incentives that were paid to the P4P intervention facilities or because of the maturity or repeated exposures to the measurement instrument. However, the comparison sites (blue line) have been experiencing visits by another quality assurance team since 2009 as part of the MNH project's core initiative. This team is formed with similar composition of the QAG members of the P4P OR and P4P MRA projects; but they have been using a shorter QOC checklist.

Figure 1. Quality of care score achieved by the study facilities in June 2012

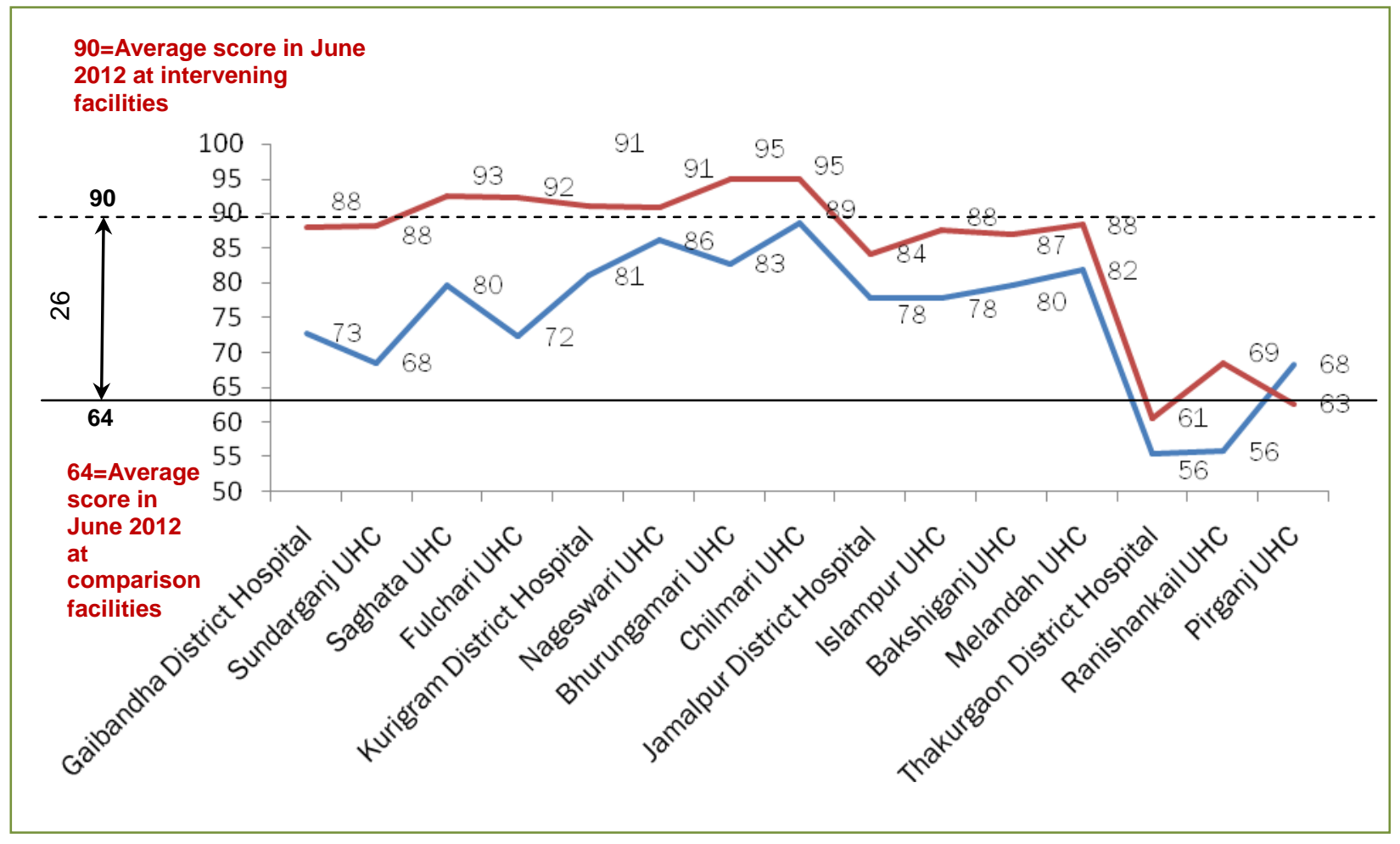

QAG visits were repeated in June 2012 to measure the changes in QOC brought by the facilities in order to meet the qualitative performance targets. At the end of the quarter, average QOC score of the intervention facilities is 90 , which is significantly higher relative to the comparison facilities that achieved average score of 64 (Appendix Table A3).

Comparison of qualitative performance between pre-intervention and intervention of 12 study facilities indicate that all facilities except Jamalpur District Hospital achieved second level qualitative targets, obtaining the score 85 percent or more on quality performance during intervention. In contrast, the highest score on quality performance obtained by comparison facilities was 68 percent, one percent above the entry level for first level of qualitative targets (Appendix Table A3).

Quality score increased remarkably for facilities in Gaibandha which had comparatively lower quality at the inception of the intervention. A relatively lower increase in quality score was observed for the facilities in Jamalpur and Kurigram which had a pre-intervention higher quality score. Improvement in 
quality of services at the intervention facilities can be attributed to two interventions: (i) implementation of a system of regular performance review and reporting through unit-based "quality assurance teams" within the facility, and (ii) the performance assessment and mentoring by the external body, known as "quality assurance group". In contrast, despite having a longer exposure to quality assurance by an external body akin to P4P one, increase in quality score of the control facilities is infinitesimal.

\section{CLIENT EXIT INTERVIEWS}

Client perspective on maternal health services ${ }^{2}$ was analyzed to measure the quality of those services, which implies the level of client satisfaction too. A weighted composite quality score was constructed based on a maximum of five processes or aspects: diagnosis (medical history and physical examination), provider availability, waiting time, counseling and follow-up, and not requiring extra money for receiving services. Comparison of composite score across the facilities reveal a higher quality of maternal health services being provided at the intervention facilities as reported by clients compared to comparison facilities. Quality score obtained is the highest for the delivery services, followed by ANC while it is discouraging for PNC.

For delivery services, diagnosis covered checking vital signs like pulse and blood pressure, palpitating abdomen and listening to fetal heartbeat, checking for edema, measuring uterus, and examining eye, provided full privacy is maintained. Provider availability was measured in terms of whether delivery service is provided by doctor or nurse, post-delivery service by doctor or nurse, doctors visited admitted patient at least once daily, and round-the-clock availability of providers. Waiting time is considered to improve the quality of services of the facility if a pregnant woman spent less than 30 minutes to get admission after reaching hospital, to get transferred from outdoor/emergency to ward or to be visited by a doctor after reaching the ward. Counseling and follow-up included advices on breastfeeding, nutrition and tetanus vaccination, Vitamin-A and iron/folic acid supplementation, advice about post-partum complications for emergency care, family planning counseling, and counseling on follow-up visit.

Composite quality score on delivery services reveals that the facilities in Jamalpur district outperformed all other facilities by more than 20 percentage points. Greater variability is observed across intervention and control for each of the processes. A wide difference was observed between intervention districts too. A high score of 89 on diagnosis for Jamalpur district indicates that providers carried out a comprehensive medical history and physical examination at its intervention facilities. For other intervention facilities (Gaibandha and Kurigram) and comparison facilities, it is yet to be a common practice in taking a comprehensive medical history and conducting a thorough physical examination. Similarly, quality score on waiting time was significantly higher for the facilities in Jamalpur followed by Kurigram compared with the facilities in control district $(89,81$ and 74 respectively). Gaibandha and Thakurgaon are lagging behind Kurigram and Jamalpur on the availability of providers. On counseling and follow-up, the facilities in Jamalpur, obtaining score of 100 , outperformed enormously all other facilities. Quality score on counseling and follow-up was

\footnotetext{
2 Maternal health services includes antenatal care, delivery, postnatal care
} 
below 70 in other districts, which indicates lapses on providing advices and preventive services. Client satisfaction level was significantly higher at the intervention sites as women did not have to pay extra money to get the services in 99 percent cases against 77 percent reported at comparison facilities (Table 5).

Table 5. Client's opinion on quality of care in receiving delivery services across arms (in percent)

\begin{tabular}{|c|c|c|c|c|}
\hline \multirow[t]{2}{*}{ Quality indicator } & \multicolumn{3}{|c|}{ Intervention } & \multirow{2}{*}{$\begin{array}{l}\text { Comparison } \\
\text { Thakurgaon }\end{array}$} \\
\hline & Gaibandha & Kurigram & Jamalpur & \\
\hline \multicolumn{5}{|l|}{ Delivery services } \\
\hline $\begin{array}{l}\text { Conducted necessary diagnosis (medical } \\
\text { history and physical examination) }\end{array}$ & 62 & 64 & 89 & 71 \\
\hline Provider availability & 71 & 84 & 83 & 72 \\
\hline Waiting time less than 30 minutes & 72 & 81 & 89 & 74 \\
\hline Counseling and follow-up & 55 & 44 & 100 & 62 \\
\hline Did not pay extra money & 100 & 98 & 99 & 77 \\
\hline Composite score (weighted) & 66 & 66 & 92 & 69 \\
\hline $\mathrm{N}$ & 93 & 73 & 73 & 53 \\
\hline \multicolumn{5}{|l|}{ ANC services } \\
\hline $\begin{array}{l}\text { Conducted necessary diagnosis (medical } \\
\text { history and physical examination) }\end{array}$ & 66 & 72 & 84 & 59 \\
\hline Waiting time less than 30 minutes & 93 & 88 & 81 & 86 \\
\hline Birth planning counseling & 26 & 18 & 80 & 18 \\
\hline Preventive care and follow-up & 56 & 62 & 98 & 54 \\
\hline Did not pay extra money & 100 & 98 & 95 & 100 \\
\hline Composite score (weighted) & 50 & 51 & 87 & 45 \\
\hline N & 29 & 57 & 37 & 28 \\
\hline \multicolumn{5}{|l|}{ PNC services* } \\
\hline $\begin{array}{l}\text { Conducted necessary diagnosis (medical } \\
\text { history and physical examination) }\end{array}$ & 31 & $\mathrm{n} / \mathrm{a}$ & 66 & 25 \\
\hline Waiting time less than 30 minutes & 96 & $\mathrm{n} / \mathrm{a}$ & 96 & 100 \\
\hline Counseling and follow-up & 48 & $\mathrm{n} / \mathrm{a}$ & 98 & 65 \\
\hline Did not pay extra money & 100 & $\mathrm{n} / \mathrm{a}$ & 100 & 100 \\
\hline Composite score (weighted) & 38 & $\mathrm{n} / \mathrm{a}$ & 74 & 37 \\
\hline $\mathrm{N}$ & 25 & 1 & 23 & 18 \\
\hline
\end{tabular}

* Kurigram excluded from analysis due to paucity of responses. 
Aspects or processes considered for the composite quality score are not constant across services. Besides, the number of indicators for each of the processes varies according to the types of services. For ANC services, it is more important to explore the quality of birth planning counseling than roundthe-clock provider availability as ANC services are provided six days a week from 8:00 am to 2:00 pm.

Comparison of composite score on ANC services across the facilities indicates a nearly similar trend to that of delivery service - higher quality of ANC services provided at the intervention facilities compared to comparison facilities. Facilities in Jamalpur district rendered highest quality ANC services, however, no remarkable difference was observed in case of waiting time and not requiring extra payment across facilities. All the intervention facilities performed better than comparison facilities in undertaking necessary diagnosis covering both medical history and physical examination. Birth planning counseling, the backbone of ANC service, is the area where most of the facilities are struggling except the facilities in Jamalpur district. A large variation was observed in the quality score on birth planning counseling between Jamalpur and other districts (80 percent vs. $18-26$ percent). Nearly similar difference holds true for preventive care and follow-up. It is universal for the intervention facilities in Jamalpur district in giving advice or preventive care including follow-up services $^{3}$. In contrast, the preventive care or advice provided in three other districts was less comprehensive, obtaining an approximate score of 60 out of 100 (Table 5).

Composite quality score on PNC services was highest for the facilities in Jamalpur district (74 percent). Small differences were observed between Gaibandha and Thakurgaon districts (38 vs. 37 percent). Kurigram district was excluded from the analysis due to the paucity of samples. Among the four service processes or aspects, lowest score on the diagnosis for PNC services suggests a great deal of opportunity for improvement (Table 5). Diagnosis for PNC is a comprehensive process which included examination of both mother and child, covering 24 service indicators (not shown in the table).

Client perspective on ANC, delivery and PNC services discussed above covers only two out of eleven service units that QAG members assess during their quarterly visit to the facility. These findings, thus, display a segment of the aggregate quality of services provided at the facility.

\section{IN-DEPTH INTERVIEWS WITH CLIENTS}

In-depth interviews with respondents reported several advantages and constraints or challenges the clients faced in receiving the services. Clients reported better quality of services provided at P4P facilities relative to comparison facilities.

Financial incentives paid to the providers affected their behavior towards the clients at the intervention sites in a limited scale, yet with disparities across intervention sites. Intervention facilities outperformed comparison facilities in providing free treatment, maintaining privacy during

\footnotetext{
${ }^{3}$ Advice on nutrition and pregnancy care, tetanus vaccine, uptake of Vitamin A, providing iron/folic acid supplementation, advice about danger signs for emergency help, advice to take ANC, delivery and PNC from skilled person, and making request for follow-up visit.
} 
physical examination, performing regular visits made by doctors and nurses, and making transport available for referral. No notable difference was observed between intervention and comparison sites regarding waiting time to get admission and in terms of providing advice on complications during pregnancy. Higher level of satisfaction in terms of receiving some medicines free-of-cost from the hospital was reported by clients from intervention sites (Table 6).

Table 6. Advantages and challenges faced in the facilities, as reported by in-depth interview respondents across arms (in number)

\begin{tabular}{|c|c|c|c|c|}
\hline \multirow[b]{2}{*}{ Advantages/challenges } & \multicolumn{3}{|c|}{ Intervention } & \multirow{2}{*}{$\begin{array}{l}\text { Comparison } \\
\text { Thakurgaon }\end{array}$} \\
\hline & Gaibandha & Kurigram & Jamalpur & \\
\hline \multicolumn{5}{|l|}{ Advantages } \\
\hline $\begin{array}{l}\text { Doctors, nurses and other service } \\
\text { providers are well behaved }\end{array}$ & 10 & 7 & 8 & 11 \\
\hline $\begin{array}{l}\text { Received free treatment from the } \\
\text { hospital }\end{array}$ & 9 & 11 & 8 & 6 \\
\hline $\begin{array}{l}\text { Patients do not have to wait long for } \\
\text { admission }\end{array}$ & 5 & 6 & 6 & 6 \\
\hline $\begin{array}{l}\text { Privacy maintained during physical } \\
\text { examination }\end{array}$ & 6 & 6 & 8 & 5 \\
\hline $\begin{array}{l}\text { Received advice on complications during } \\
\text { pregnancy/ child care/ vaccination }\end{array}$ & 4 & 8 & 8 & 7 \\
\hline Doctors came regularly on visit & 7 & 5 & 5 & 5 \\
\hline Nurse came regularly on visit & 9 & 7 & 3 & 2 \\
\hline $\begin{array}{l}\text { Some medicines are provided by the } \\
\text { hospital }\end{array}$ & 2 & 9 & 8 & 0 \\
\hline $\begin{array}{l}\text { Availability of transport to reach the } \\
\text { hospital }\end{array}$ & 12 & - & 11 & 6 \\
\hline \multicolumn{5}{|l|}{ Challenges } \\
\hline $\begin{array}{l}\text { No advice given on newborn care, post } \\
\text { pregnancy complications and care }\end{array}$ & 5 & 3 & 3 & 7 \\
\hline No advice offered on family planning & 2 & 2 & - & 1 \\
\hline Did not get all necessary medicines & 3 & 2 & 7 & 5 \\
\hline Food not supplied from the hospital & 2 & - & 5 & 1 \\
\hline Vehicle problem to reach the hospital & - & 2 & 2 & - \\
\hline $\begin{array}{l}\text { Have to pay extra money for services (to } \\
\text { support staff) }\end{array}$ & 3 & 1 & 1 & 5 \\
\hline $\mathrm{N}$ & 12 & 12 & 12 & 11 \\
\hline
\end{tabular}


Providers at the intervention facilities were not regular in giving advice on complications regarding newborn care, post pregnancy complications and care, yet, intervention sites were twice as likely as comparison sites to give such advice. Overall, half of the respondents at the comparison sites reported not getting all necessary medicines and providing extra payments to receive services as cause of dissatisfaction. Some of these challenges exist for intervention facilities, but to a lower extent. On the contrary, comparison sites performed better than intervention facilities in providing food to the admitted clients (Table 6). Often, clients get admitted even after all beds are occupied, which is common in Jamalpur. Clients admitted without beds are not provided food, which may be reported as "food not supplied" in the interviews.

Case study 1, extracted from a client in-depth interview of Gaibandha district, depicts the quality of care received by a poor pregnant woman for institutional delivery and PNC services. This case study also revealed how availability and regular visits by doctors and nurses along with their good behavior impact upon the satisfaction level of the clients even if the clients incurred cost to receive services.

Case study 1. Providing quality of care is the key to increase institutional delivery

Fatema (fictitious name) delivered her first child at home when she was 21 years old while the second one was delivered at the hospital. Fatema's husband is a day laborer. Neither her husband nor Fatema had ever been to school. Despite not knowing how many antenatal care visits should be made during pregnancy, Fatema attained four antenatal care services from the hospital. Fatema experienced three days of labor pain during her first delivery, which took place at home. Her maternal grandmother assisted during the delivery. For her second labor, Fatema was taken to the nearby upazila hospital. Fatema had to wait for half an hour, but she didn't face any problem during her admission. A nurse performed her physical examination by maintaining privacy. Doctors behaved well and came at 10 am everyday on visit. Nurses came on regular visits and checked both the mother and the child. Fatema was advised on breastfeeding and newborn child care. She stayed at the hospital for 3 days and 3 nights. Later, Fatema visited the hospital for receiving postnatal care service when both Fatema and her child were examined. She also received advice on family planning methods. Fatema had to spend 320 taka (\$3.90) - medicine 110 taka, transportation 80 taka, food 80 taka and others 50 taka - during delivery and 55 taka (\$0.67) for post natal care services. According to Fatema, the expenditure was not very high - the treatment was free and she got some medicines for free. Overall quality of service was satisfactory. She believes that it is better to deliver at hospitals, because these facilities have better amenities for safe delivery than home.

25 years old, female, married, housewife, mother of 2 children Prepared by: Eashita Farzana Haque, Population Council 


\section{IN-DEPTH INTERVIEWS WITH PROVIDERS}

From 12 intervention facilities, 5 managers, 5 consultants, 7 medical officers and 11 senior staff nurses were interviewed with the purpose to track the changes in service delivery the providers experienced in the course of the P4P project and extract their opinion on how to sustain the innovations of the project. Innovation in human resources and quality assurance tested by P4P interventions has contributed to a remarkable improvement in the performance of facilities.

Respondents were asked whether P4P caused any changes in human resources in terms of availability, skills, accountability, and team work. Most of the respondents (23 out of 28 ) appreciated the P4P contribution in improving the skills, ensuring accountability of service providers and promoting teamwork, which enabled the facility to achieve both quantity and quality goals. Twenty one respondents reported improvement in provider availability. Facilities in Jamalpur
"P4P has helped to improve skills of providers at three levels: technical, managerial and supervisory. Our technical skills have been improved as a result of $Q A G$ visit. QAG visit by three specialists - obstetrician, anesthesiologist and pediatrician - acts as refresher training, as providers of the hospital learns new skills from those senior professionals. QAG tool enables the monitoring experts to acquire systematic supervisory skills. On the other hand, QAT is a useful mechanism to ensure coordination and hone managerial skills."

- A manager of a District Hospital and Kurigram were able to improve the regularity and availability of providers while it is still a challenge for the facilities in Gaibandha, which are chronically plagued with the shortage of providers.

P4P project is highly acclaimed by the respondents for institutionalizing a systematic quality assurance mechanism. All 28 respondents found both the QAG visit by external higher-level body for mentoring providers and the weekly QAT meeting for addressing internal quality gaps immensely

"We did not have weekly, monthly and quarterly meetings at different levels prior to the P4P project. Meetings aided with organized tools for ensuring coordination and improving quality of services at different levels is a new idea for us. These meetings help us to identify deficiency and problems in service delivery and to take measures accordingly. QAT tool, consisting of a list of requisite equipments, drugs and supplies for a service unit, is particularly useful at the micro level, which describes the readiness and requirements of a unit, expediting decision-making."

- A medical officer of an Upazila Health Complex useful. QAT tool's effectiveness in ensuring readiness of service units and the impact of QAG visit in enhancing the provider capacity have been recognized by all service providers. All respondents strongly recommended extending the blend of both external and internal quality assurance beyond $\mathrm{MNCH}$ services. 
All the respondents acknowledged the individual benefits they acquired from the P4P initiative. The most frequently cited benefits are: acquiring new skills or receiving on-the-job training; developing team dynamics and interpersonal relations; psychological contentment; and earning extra income through incentive. Table 7 highlights the benefits at the facility level, particularly the major changes of selected service units that have been caused by the P4P interventions and the opinions of respondents on how to sustain those improvements.

Table 7. Improvements in service delivery and sustainability measures as reported by providers

\begin{tabular}{|c|c|c|}
\hline Service unit/area & Improvements & How to sustain improvements \\
\hline Emergency room & $\begin{array}{l}\text { - } \text { Availability of service providers, logistics and } \\
\text { drugs } \\
\text { - } \quad \text { Cleanliness and sterilization } \\
\text { - } \quad \text { Privacy fully maintained } \\
\text { - } \quad \text { Sitting arrangement for attendants }\end{array}$ & $\begin{array}{l}\text { - } \\
\text { Ensuring manpower } \\
\text { drugs } \\
\text { - } \quad \text { Regular unit-based team work } \\
\text { and meeting, and use of QAT } \\
\text { tool }\end{array}$ \\
\hline Delivery room & 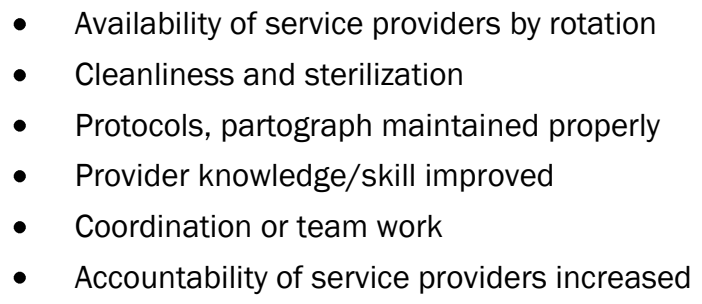 & $\begin{array}{l}\text { - Regular unit-based team work } \\
\text { and meeting, and use of QAT } \\
\text { tool } \\
\text { - Supervision by specialists from } \\
\text { higher-level facility (QAG visit) }\end{array}$ \\
\hline Medicine supply & $\begin{array}{ll}\text { - } & \text { Fund for emergency medicines } \\
\text { - } & \text { Regular and adequate drug supply }\end{array}$ & $\begin{array}{l}\text { - } \quad \text { Creating a new fund } \\
\text { Regular supervision through } \\
\text { QAT meeting and tool } \\
\text { - } \quad \text { Regular coordination and } \\
\text { supervision by administrative } \\
\text { authority (CS/UHFPO/RMO) }\end{array}$ \\
\hline Infection prevention & $\begin{array}{ll}\text { - } & \text { Sterilization ensured } \\
\text { - } & \text { Protocol followed }\end{array}$ & $\begin{array}{l}\text { - } \quad \text { Training for service provider } \\
\text { Regular supervision through } \\
\text { QAT meeting and tool } \\
\text { - } \quad \text { Availability of logistic and } \\
\text { electric supply }\end{array}$ \\
\hline Waste management & $\begin{array}{l}\text { - Use of separate color bins } \\
\text { - Incineration, dumping, burning properly } \\
\text { - } \quad \text { Protocol followed }\end{array}$ & $\begin{array}{ll}\text { - } & \text { Training for service providers } \\
\text { - } & \text { Regular coordination and } \\
\text { supervision by administrative } \\
\text { authority (CS/UHFPO/RMO) }\end{array}$ \\
\hline
\end{tabular}

Analysis of the findings presented in Table 7 identified two innovations, quality assurance group and quality assurance team, that need to be continued, for which ensuring manpower and refresher training of service providers and other staff are required. It is apprehended that in the absence of incentive for providers, QAG visits are unlikely to make the facilities bring changes to the systems. Service unit based QATs, however, can be strengthened further through regular coordination and supervision by administrative authority (CS/UHFPO/RMO) in order to sustain the improvements caused by P4P interventions. 
Findings from in-depth interviews with providers indicate the importance of continuing institutionbased provider incentives for MNCH services. The existing P4P model, however, has scopes for improvement. While in outlining the future P4P model, the respondents were divided. Respondents in Gaibandha and Jamalpur opined that unit-based targets instead of facility-based targets will be more useful and reduce the dissatisfaction among high-performing providers. Not all Upazila Health Complexes in a district are covered by the current P4P project. Majority of the respondents reasoned that inclusion of all Upazila Health Complexes would create a competition among the facilities.

Case study 2 portrays how the quality of $\mathrm{MNCH}$ services has been improved as a consequence of the introduction of facility-based incentives for providers. Incentives make the service providers more accountable and efficient, which is pivotal to improve the quality of care of facilities.

\section{Case study 2. Facility responding to the P4P incentives to improve quality of $\mathrm{MNCH}$ services}

Dr. Nayeem (fictitious name), with 27 years of working experience and 3 years services at the current facility, gave a detail account of the improvement that the facility underwent during the P4P project period. Facility amenities were improved with enhancement of overall cleanliness, establishment of citizen charter, marking of service point, separation of labor room and operation theater, introduction of ante- and post-natal care corner, breast feeding corner, separate sitting arrangements by gender, improvement of infection prevention and autoclaving. Availability of drugs and consumables was also improved. Regular meeting of Quality Assurance Team (QAT) and P4P Committee enhanced providers' availability. Regular supervision, mentoring and counseling offered by the Quality Assurance Group (QAG) members from Medical Colleges as well as mentoring from the in-house QAT team leaders increased provider skills in offering better MNCH services. According to Dr. Nayeem, P4P Committee and the QAT have improved the provider accountability; however, more power can be vested to the QAT leaders in order to enable them to address the performance of their service units, which include important MNCH service delivery points (ANC/PNC corner, emergency room, autoclave room, operation theater, labor room, obstetrics ward, pediatrics ward, pharmacy, laboratory and store).

With regard to incentives, Nayeem confirmed that incentives make the service providers more efficient; and this is pivotal to improve the quality of care. Incentives, however, could be distributed according to the performance of individual service units of the facility instead of measuring the performance of the facility as a whole, because non-performance of one unit may affect the target achievement of the whole institution. This prevents the performing units to get the reward.

An Obstetrics-Gynecology Consultant 


\section{PROVIDER SURVEY}

Provider motivation is measured in terms of supervision, teamwork and recognition. Encouragingly, 100 percent providers in two intervention districts (Kurigram and Jamalpur) reported regular monitoring by their supervisors compared to 94 percent in the control district (Thakurgaon). Nearly similar trend is observed for receiving supervisory feedback. Facilities in Jamalpur outperformed all other districts in receiving regular feedback from the supervisors while it was lowest in Gaibandha. Regarding supervisory visit from higher-level facility, the proportion of providers in control district received such visit was the lowest compared to intervention districts. Almost all providers in Kurigram and Jamalpur districts received supervisory visit from higher-level facilities (Table 8).

Table 8. Provider supervision, teamwork and motivation across intervention and control sites (in percent)

\begin{tabular}{|c|c|c|c|c|c|c|c|}
\hline & \multicolumn{3}{|c|}{ Intervention } & \multirow{2}{*}{$\begin{array}{c}\text { Control } \\
\text { Thakur- } \\
\text { gaon }\end{array}$} & \multirow{2}{*}{$\begin{array}{l}\text { Gaibandha } \\
\text { vs. } \\
\text { Thakurgaon }\end{array}$} & \multirow{2}{*}{$\begin{array}{c}\text { Kurigram } \\
\text { vs. } \\
\text { Thakurgaon }\end{array}$} & \multirow{2}{*}{$\begin{array}{c}\text { Jamalpur } \\
\text { vs. } \\
\text { Thakurgaon }\end{array}$} \\
\hline & $\begin{array}{c}\text { Gai- } \\
\text { bandha }\end{array}$ & $\begin{array}{l}\text { Kuri- } \\
\text { gram }\end{array}$ & $\begin{array}{c}\text { Jamal- } \\
\text { pur }\end{array}$ & & & & \\
\hline & & & & & \multicolumn{3}{|c|}{$Z$ test value and level of significance } \\
\hline \multicolumn{8}{|l|}{ Supervision } \\
\hline $\begin{array}{l}\text { Supervisor monitors } \\
\text { regularly }\end{array}$ & 79 & 100 & 100 & 94 & $2.61 * *$ & $2.19 *$ & $2.65 *$ \\
\hline $\begin{array}{l}\text { Supervisor provides regular } \\
\text { feedback }\end{array}$ & 57 & 87 & 97 & 88 & $4.17 * * *$ & 0.16 & $2.55^{*}$ \\
\hline $\begin{array}{l}\text { Supervisory visit from } \\
\text { higher facility in last } 6 \\
\text { months }\end{array}$ & 66 & 96 & 99 & 49 & $2.14 *$ & $6.58 * * *$ & $8.38 * *$ \\
\hline \multicolumn{8}{|l|}{ Teamwork } \\
\hline $\begin{array}{l}\text { Follows guideline for } \\
\text { group work }\end{array}$ & 24 & 56 & 60 & 41 & $2.19 *$ & 1.76 & $2.45 *$ \\
\hline $\begin{array}{l}\text { Teamwork ensures } \\
\text { appropriate staff mix }\end{array}$ & 40 & 66 & 42 & 3 & $5.38 * * *$ & $7.89 * * *$ & $5.71 * * *$ \\
\hline $\begin{array}{l}\text { Teamwork improves } \\
\text { quality of care }\end{array}$ & 54 & 77 & 51 & 6 & $6.24 * * *$ & $8.68 * * *$ & $6.26 * * *$ \\
\hline \multicolumn{8}{|l|}{ Recognition } \\
\hline $\begin{array}{l}\text { Received recognition } \\
\text { for good } \\
\text { performance from } \\
\text { the supervisor }\end{array}$ & 57 & 80 & 79 & 85 & $3.72 * * *$ & 0.88 & 1.12 \\
\hline $\begin{array}{l}\text { Expects financial } \\
\text { incentive for working } \\
\text { in rural areas }\end{array}$ & 96 & 96 & 98 & 88 & 1.90 & 1.83 & $2.92 * *$ \\
\hline $\begin{array}{l}\text { Expects recognition } \\
\text { in the form of } \\
\text { training }\end{array}$ & 15 & 75 & 63 & 50 & $4.68 * * *$ & $3.10 * *$ & 1.76 \\
\hline $\mathrm{N}$ & 82 & 79 & 116 & 68 & & & \\
\hline
\end{tabular}


The provider survey also indicated higher likelihood of compliance of guidelines for group work by the intervention facilities - facilities in Kurigram and Jamalpur districts were more likely to follow structured guidelines relative to comparison facilities. Perception of benefits of teamwork clearly distinguishes the intervention facilities from the control facilities. Approximately half of the providers in intervention districts reported the benefits of teamwork in ensuring appropriate distribution of responsibilities among staff members as well as improving quality of care. In contrast, a negligible proportion of providers ( 6 percent or less) from control district perceived such benefits from teamwork (Table 8).

Providers at comparison facilities were more likely to receive appreciation for good performance from the supervisor, followed by Kurigram and Jamalpur. Facilities in Gaibandha are yet to make it customary to receive regular recognition and appreciation from supervisors. Regardless of the exposure to interventions, providers were unanimous in voicing the necessity of financial incentive for working in rural areas. Approximately half of the providers expected recognition for their performance in the form of training, where the proportion of providers in one intervention district mentioned such need was remarkably low (Table 8).

\section{DEATH REVIEWS}

The "Three Delay Model" is used to determine the causes of maternal and neonatal deaths: delay in deciding to seek care, delay in reaching facility in time, and delay in receiving adequate treatment. In two districts, 92 newborns and 2 women died at the facility during the three-month intervention period (March-May 2012). All these deaths were systematically reviewed to determine the causes of deaths.

\section{CAUSES OF NEWBORN DEATHS}

District Hospital reported 90 and Upzaila Health Complexes 2 newborn deaths. An analysis of causes of deaths by using a three-delay model attributed the first two delays to most of the neonatal deaths. Review meetings of MPDR Committee revealed that majority of the deaths occurred due to delay to reach the facility. However, the delay to recognize a life-threatening condition or an emergency when births occur at home (first delay) was found as the primary reason for deaths. Neonates who died at the facility had been delivered at home by community-level providers, who lack the skill to predict or prevent bad outcomes and medical knowledge to diagnose and immediately act on complications. Inappropriate or arbitrary use of oxytocin by community-level unskilled providers and low quality of ANC services provided by NGO fieldworkers contributed to neonatal deaths in many cases. Low uptake of ANC services by women is another contributing factor for neonatal deaths.

Managers of the facilities reported delayed referral of newborns with critical situation by communitylevel providers and local private clinics. Second delay to reach the facility worsened the condition further towards death. Ninety percent of the neonates were admitted with life-threatening, unstable condition and four percent of neonates died upon arrival at the facility prior to indoor admission (Table 9). Remaining six percent of the neonatal deaths can be attributed to inadequate service provision of the facility. 
Table 9. Review of newborn and maternal deaths occurred at facilities in Gaibandha and Kurigram (in numbers)

\begin{tabular}{|c|c|c|c|c|c|}
\hline \multirow[t]{2}{*}{ Category } & \multicolumn{2}{|c|}{ Newborn deaths } & \multicolumn{3}{|c|}{ Maternal deaths } \\
\hline & Gaibandha & Kurigram & Gaibandha & Kurigram & \\
\hline \multicolumn{6}{|l|}{ Condition } \\
\hline Unstable during outdoor admission & 44 & 38 & 2 & & - \\
\hline Death at outdoor admission & 1 & 3 & - & & - \\
\hline Referred from Upazila Health Complex & 5 & 10 & $n / a *$ & & - \\
\hline \multicolumn{6}{|l|}{ Admission time } \\
\hline $8: 00$ am to $2: 00 \mathrm{pm}$ & 19 & 16 & - & & - \\
\hline $2: 00 \mathrm{am}$ to $8: 00 \mathrm{pm}$ & 16 & 12 & 1 & & - \\
\hline $8: 00 \mathrm{pm}$ to $8: 00 \mathrm{am}$ & 12 & 15 & 1 & & - \\
\hline $\begin{array}{l}\text { Immediate transfer of referred cases to } \\
\text { indoor or labor room }\end{array}$ & 43 & 45 & 2 & & - \\
\hline $\begin{array}{l}\text { Deaths occurred from arrival to indoor } \\
\text { admission }\end{array}$ & 0 & 0 & 0 & & - \\
\hline Pregnancy outcome: Live birth & $\mathrm{n} / \mathrm{a}$ & $\mathrm{n} / \mathrm{a}$ & 2 & & - \\
\hline $\mathrm{N}$ & 47 & 45 & 2 & & - \\
\hline
\end{tabular}

* Deaths took place at Upazila Health Complexes

Review of medical aspects of neonatal deaths occurred at the facility revealed that the majority of neonatal deaths was due to perinatal asphyxia, sepsis and birth trauma. Prolonged labor, inappropriate use of oxytocin, labor by unskilled providers and poor skills in identifying high-risk mother were identified as the underlying causes of asphyxia, sepsis and birth trauma. MPDR Committee affirmed that almost all deaths were due to delay in reaching the facility. Findings from Table 9 corroborate this statement. Ninety-four percent of the referred newborn cases were received in an unstable condition or dead. Eighty-four percent of these cases were referred by either unqualified or community-level providers. No death occurred from the arrival of newborns at the facility to transferring to the ward. Round-the-clock availability of providers (both doctors and nurses) could not prevent death of those critical cases. Yet, a small proportion of deaths occurred due to the third delay at health facility, due to several supply-side factors, which include lack of inputs, e.g., technology or services necessary to provide critical care, unavailability of pediatrician at referring facilities, and not fully complying treatment procedure (not shown in the table).

\section{CAUSES OF MATERNAL DEATHS}

Maternal deaths took place at two UHCs in Gaibandha. Review of medical aspects of these deaths found severe PPH and anemia as causes of deaths. Community-level providers with their limited medical knowledge could not recognize life threatening condition in these women and predict bad outcomes either (first delay). 
Both cases were admitted with critical condition, but attended on time by doctors. Doctor in one facility did not have any EOC training. Deaths occurred at night - one died after three hours of admission and the other after six hours. Round-the-clock availability of doctors and nurses was not sufficient to prevent death of those critical cases. No lapse in assessment, clinical treatment with available technology and skills, and prevention of infection was found, but management of PPH by blood transfusion was the key service provision missing at both the facilities.

The key reason for these deaths is the inadequate care women received at the community level and upon arrival at the facility. Supply-side factors responsible for these deaths include lack of inputs, e.g., blood transfusion, unavailability of EOC-trained doctor at receiving facilities, and lack of skills among community-level providers to identify high-risk mothers. On the other hand, patients are less inclined to go to higher facility if referred. One woman was advised referral to higher-level hospital but her attendant could not make timely decision. First and third delays related to services women received at home and the facility contributed to two maternal deaths reviewed.

\section{INCENTIVE LEVEL ACHIEVEMENT}

Incentive level is determined based on the performance level achieved for both the quantitative and qualitative targets. Achieving the first and second level of targets enables the facilities to meet the first and second level of incentives, respectively. For achieving the first level of incentive, the facilities must meet, at least, the first level of both quantitative and qualitative targets. Similarly, for achieving the second level of incentive, the facilities must meet the second level of quantitative and qualitative targets.

Quantitative targets are set on ANC, delivery and PNC services based on the past quarter's performance levels. Targets vary across facilities as facilities that have, historically, been performing at a very low level are assigned higher targets in anticipation of larger increase in service volume, with the purpose to minimize the cost of incentive per institutional delivery. Qualitative targets are set on obtained quality score on a 100 point scale. Facilities need to achieve at least 67 and 85 out of 100 for achieving the first and second level qualitative targets, respectively.

Out of the 12 facilities, 10 facilities achieved incentives for achieving both the quantitative and qualitative targets. Seven facilities performed at the second level while three facilities performed at the first level. Gaibndha is the only district where all four intervention facilities achieved performance incentives. One facility each in Kurigram and Jamalpur did not achieve the targets for service volumes, thus failed to receive any incentive for non-performance. Quantitative performance of Jamalpur District Hospital and Nageshwari UHC fell short of targets, due to shortage of adequate number of obstetricians. Moreover, Nageshwari UHC also faced infrastructural problems due to facility renovation activities. 
Table 10. Level of incentive achieved by intervention facilities

\begin{tabular}{lrrrr}
\hline Levels of incentive achieved & Gaibandha & Kurigram & Jamalpur & Total \\
\hline $1^{\text {ST }}$ level incentive & 1 & 2 & - & 3 \\
$2^{\text {ND level incentive }}$ & 3 & 1 & 3 & 7 \\
No incentive received & - & 1 & 1 & 2 \\
\hline Total & 4 & 4 & 4 & 12 \\
\hline
\end{tabular}

\section{FUND MANAGEMENT}

The 12 intervention facilities spent US\$68,651 in March to May 2012 quarter for providing incentives to the providers and fieldworkers and for acquiring essential drugs, supplies and consumables not being provided by the government system. Forty percent of the total liquidated amount was spent by facilities of Gaibandha district, 35 percent by Jamalpur and the remaining 25 percent by Kurigram. The proportion of liquidated amount was lower for facilities of Jamalpur and Kurigram districts relative to Gaibandha, because one facility from each of these two districts failed to meet any level of incentive target. The proportion of fund liquidated in Kurigram was lower than Jamalpur because Jamalpur had more beneficiaries due to the presence of higher number of eligible beneficiaries, and they also performed at higher level than Kurigram ${ }^{4}$. Almost all the fund (97 percent) was spent for providing incentives to the providers (Figure 2).

Figure 2. Distribution of liquidated expenses by intervention districts and head of expenditures
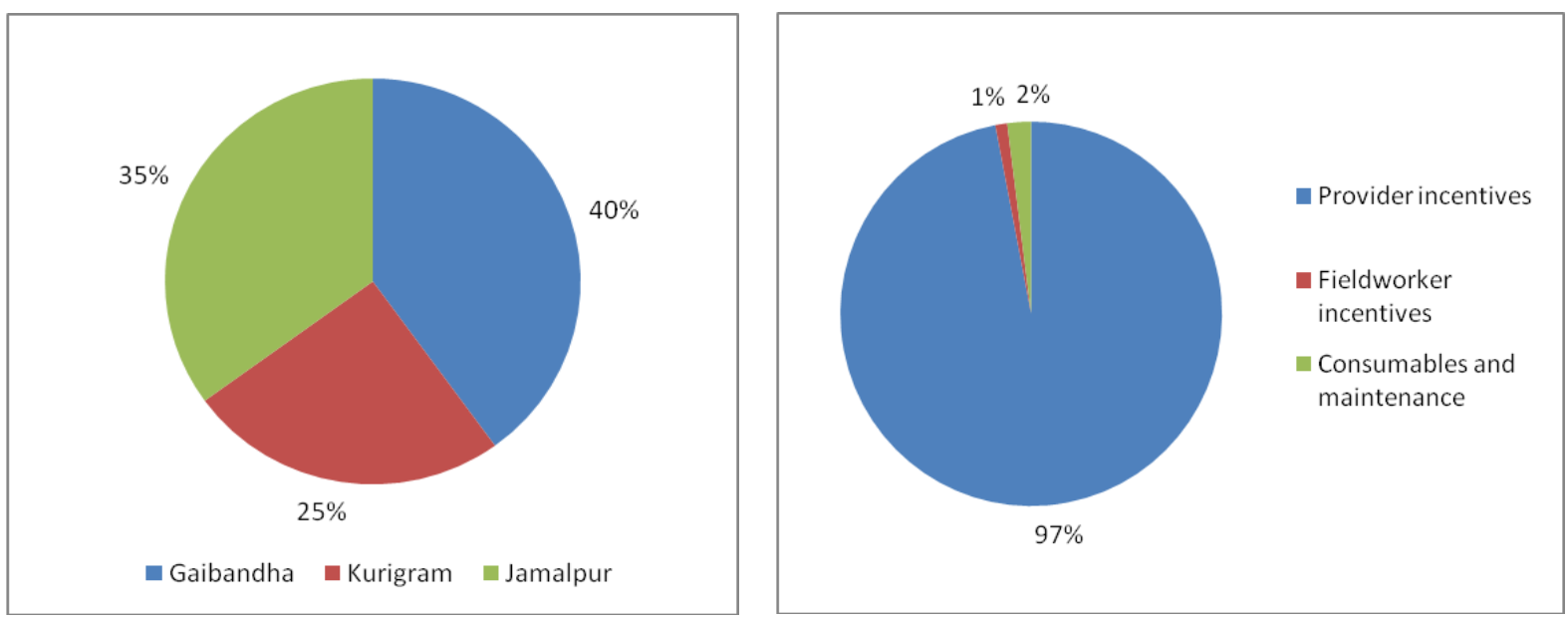

4 Two out of three performing facilities of Kurigram achieved the first level of target and the other achieved the second level of target while all the three performing facilities of Jamalpur district achieved the second level of target 


\section{INCENTIVE COSTS}

A total of 14,662 maternal health service units were delivered across the 12 intervention facilities during March to May 2012 (Table 11). Maternal health services include antenatal care, institutional delivery and postnatal care services for which the facilities had set targets. Incentive costs include the cost of incentive payments to the providers, referral incentives paid to the fieldworkers, and cost of supplies and maintenance that were incurred. Analysis of incentive cost incurred shows that the additional cost for each maternal health service unit is US\$5 only, which is lower than that incurred under the P4P OR project (US\$8). Gaibanda and Kurigram had the same unit cost of $\$ 6$ for maternal health services while Jamalpur District incurred the lowest unit cost of $\$ 3$. The reason is that Jamalpur contributed almost half of the total maternal health service units provided to the clients, but incurred only 35 percent of the total cost. Facilities of Gaibandha and Kurigram contributed to 33 and 19 percent of total maternal health service units but incurred 40 and 25 percent of total costs, which drove their unit costs higher (Table 11). All these maternal health services were provided with higher quality of care although the cost of quality cannot be separated out form the number of maternal health services delivered to the clients.

Table 11. Maternal services delivered and incentive cost per maternal service unit across intervention sites

\begin{tabular}{|c|c|c|c|c|}
\hline $\begin{array}{l}\text { Service type and cost of } \\
\text { incentives }\end{array}$ & Gaibandha & Kurigram & Jamalpur & Total \\
\hline \multicolumn{5}{|l|}{ Maternal service units } \\
\hline Institutional delivery & 556 & 560 & 893 & 2,009 \\
\hline Antenatal care & 3,230 & 1,639 & 4,256 & 9,125 \\
\hline Postnatal care & 1,063 & 612 & 1,853 & 3,528 \\
\hline Total service units & 4,849 & 2,811 & 7,002 & 14,662 \\
\hline Distribution & $33 \%$ & $19 \%$ & $48 \%$ & $100 \%$ \\
\hline \multicolumn{5}{|l|}{ Incentive cost } \\
\hline Incentive cost (US\$) & 27,340 & 17,007 & 24,304 & 68,651 \\
\hline Distribution & $40 \%$ & $25 \%$ & $35 \%$ & $100 \%$ \\
\hline $\begin{array}{l}\text { Incentive cost per maternal } \\
\text { service unit under P4P MRA } \\
\text { project (US\$) }\end{array}$ & 6 & 6 & 3 & 5 \\
\hline $\begin{array}{l}\text { Incentive cost per maternal } \\
\text { service unit under P4P OR } \\
\text { project (US\$) }\end{array}$ & 9 & 9 & 7 & 8 \\
\hline
\end{tabular}

Comparison of provider incentive cost incurred for each delivery between P4P OR, P4P MRA and DSF reveals significant differences among these three initiatives. Provider incentive cost incurred for each delivery under the P4P MRA project is US\$33, remarkably lower compared to the P4P OR study (US\$ 58) and much lower than the DSF program (US\$70) (Figure 3). 
Figure 3. Provider incentive cost per delivery across P4P OR, P4P MRA and DSF (in US\$)

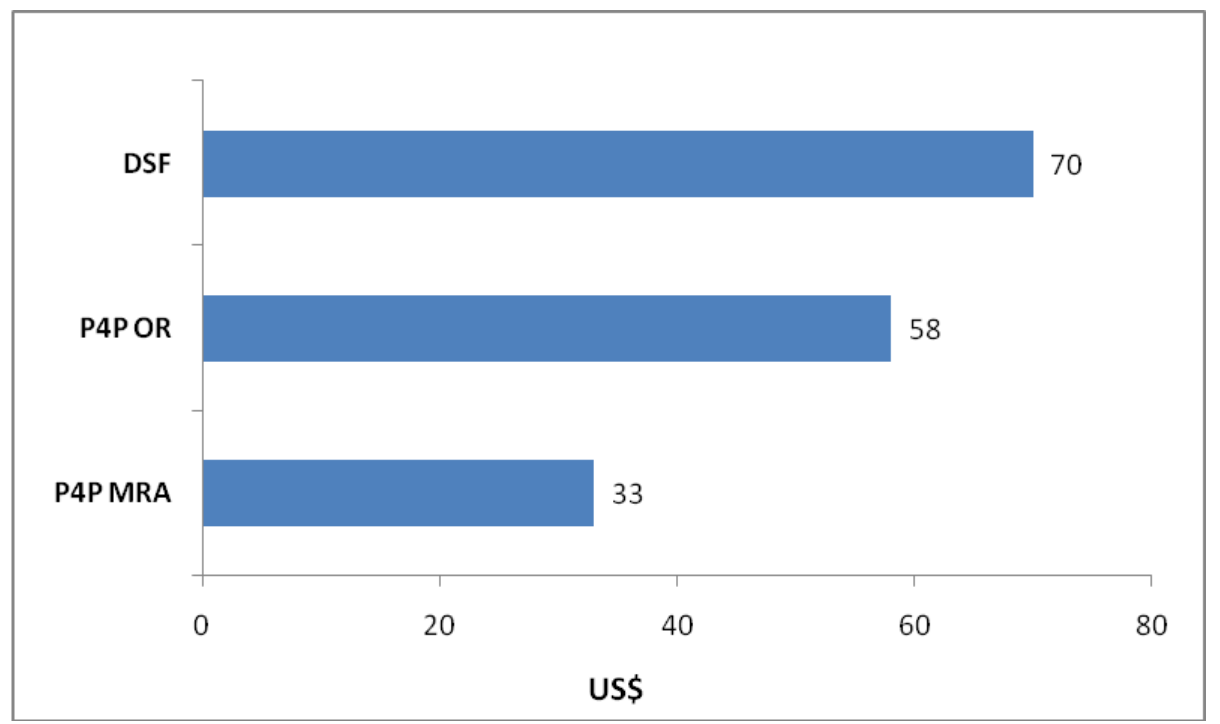

\section{SERVICE VALIDATION}

In June 2012, Council-appointed audit firm carried out service validation of institutional deliveries in six out of 10 facilities that achieved the quantitative targets. Selected six facilities, two each from Gaibandha, Kurigram and Jamalpur districts, performed 777 institutional deliveries during March to May 2012. Sixty-seven percent (524 cases) of the deliveries were selected for service validation. All the delivery clients were selected for validating the facilities that performed less than or equal to 100 deliveries. For facilities that performed over 100 deliveries, a total of 100 cases were randomly selected.

According to the validation report, overall 99 percent of the delivery records submitted by the performing facilities are valid; only 5 cases could not be identified by the auditors in the communities.

\section{ADVOCACY}

An advocacy meeting was carried out with the Joint Chief, Planning of the MOHFW and program managers of DGHS in May 2012. It was decided to hold a meeting with the Secretary, MOHFW to discuss the implications of the P4P scheme. Pursuant to the suggestion of the Director, Primary Health Care and Line Director, Maternal Newborn Child and Adolescent Health, DGHS, some outcome indicators measuring the quality of care have been decided to be included in the future QAG monitoring tool. In July 2012, as part of advocacy, a joint field visit of GOB-UNICEF-Council was organized with the Senior Secretary of the MOHFW as the team leader, accompanied by program managers of the MIS Unit, Quality Assurance under the Hospital Services and Management Unit, and DSF unit of the DGHS. 


\section{IMPLEMENTATION CHALLENGES}

In terms of implementation of the P4P MRA project, discontinuation of demand-side financing has been a major disadvantage for Gaibandha and Kurigram districts, which provided financial assistance to the poor clients in an attempt to address the inequality in accessing facility-based maternal health services under the P4P OR project. The modified P4P scheme under the P4P MRA project has been implemented only for three months; hence it was not possible to incorporate demand-side financing for pregnancy care.

Carrying out advocacy as well as refinement of the model within the limited duration of six months is challenging. The Council and UNICEF repeatedly met with the government and developing partners to enhance understanding of the P4P mechanism and its potential for improving the MNCH services for the country. A joint GOB-UNICEF-Council visit at a P4P project site was carried out at the end of the project (in July 2012), leaving inadequate time to embark on the process to scale up the initiative in a larger setting.

A six-month project with three-month intervention was peremptory in giving the flexibility to carry out advocacy activities. Strict deadline within extremely short duration forestalled the project activities synchronizing MOHFW's availability. Thus, the national-level advocacy initiative to share research findings could not been held. Nevertheless, the Council, through its extended local, regional, and international presence and networks, as well as web-based reports and scientific publications, makes the products and results of the project widely known and available.

\section{DISCUSSIONS}

The P4P MRA project considered in the report is a follow-on initiative of the P4P OR project, with a few modifications in the interventions and duration. Like the P4P OR project, the P4P MRA project provides conditional financial incentive to the $\mathrm{MNCH}$ team of a health facility for obtaining predetermined performance targets (both quantity and quality), on a quarterly basis. In addition to continuing the platform set by the P4P OR project, P4P MRA has brought three changes to the exiting interventions: (i) employing the performance incentive for providers alone by discontinuing demandside financing for poor clients; (ii) introduction of automated web-based QAG tools replacing the paper-based QAG checklists as well as inclusion of QAG visits for the comparison facilities; and (iii) instituting weekly review meetings for QATs replacing monthly meeting.

P4P MRA was implemented for a single quarter, i.e., three months (compared with the five-quarter intervention of P4P OR) and had no opportunity to lift the service volume in case of an underperformance. Nevertheless, the contribution of interventions in improving the skills of providers, ensuring availability and accountability of service providers and promoting teamwork enabled the facility to achieve both quantity and quality goals. 


\section{INCREASED SERVICE VOLUME}

Despite being inherited an increased level of service volume contributed by the five-quarter intervention of the P4P OR study, the single quarter intervention of P4P MRA brought some noticeable changes in the utilization of maternal health services, where intervention facilities increased their performance in institutional delivery by 28 percent while the comparison facilities increased their performance by 14 percent. Of 12 intervention facilities, performance of one facility in institutional delivery declined due to unavailability of obstetrician and anesthesiologist pair, and infrastructure renovation activities.

Comparison of ANC services indicates no considerable difference between intervention and control facilities. P4P MRA contributed to a remarkable improvement in the volume of PNC services, with an increase of 46 percent in the intervention facilities relative to a minimal 10 percent increase in the comparison facilities.

Higher increase in the service volume of intervention facilities is primarily due to the performance incentive tied with targets. At the same time, human resource innovation like unit-based weekly meeting and teamwork and supervisory feedback from external body contributed to such boost in performance.

\section{IMPROVED QUALITY OF CARE}

Comparison of qualitative performance between intervention and control facilities indicate that average QOC score of the intervention facilities increased to 90 from 79 over the three months of intervention, which is significantly higher relative to the comparison facilities that achieved average score of 64 from 60. Increase in quality score at the control facilities is infinitesimal despite having a longer exposure to quality assurance by an external body. Improvement in quality of services at the intervention facilities can be attributed to two interventions: QAG and QAT. Regular supervision, mentoring and counseling offered by the QAG members from higher-level facility (i.e., medical college) as well as mentoring from the in-house QAT team leaders increased providers' skills in offering better services. QATs implemented a system of regular performance review and reporting, and weekly QAT meeting addressed internal quality gaps.

\section{CLIENT SATISFACTION}

Client satisfaction was measured by analyzing client perspective on different quality aspects of maternal health services gathered through exit interviews, covering diagnosis (medical history and physical examination), provider availability, waiting time, counseling and follow-up, and not requiring extra money for receiving services. Generally, lapses in undertaking necessary diagnosis and offering necessary preventive care or counseling in maternal health services were found across facilities except the facilities in Jamalpur. Taking a comprehensive medical history and conducting a thorough physical examination during delivery service is yet to be a common practice for most facilities. For ANC service, birth planning counseling is a useful opportunity that most of the facilities miss out. 
Massive improvement is required for diagnosis of $\mathrm{PNC}$, which is a comprehensive process comprising examination of both mother and child.

Findings from in-depths reveals higher client satisfaction level at the intervention sites relative to the comparison sites. Financial incentives paid to the providers had some effect on the clients' satisfaction with the quality of care in terms of receiving some medicines free-of-cost from the hospital and not requiring to pay extra money to get the services.

\section{PROVIDER MOTIVATION AND SUSTAINABILITY}

Provider motivation is measured in terms of teamwork and individual benefits. Perception of benefits of teamwork clearly distinguishes the intervention facilities from the control facilities. Approximately half of the providers in intervention districts reported the benefits of teamwork in ensuring appropriate distribution of responsibilities among staff members as well as improving quality of care compared to a negligible proportion of providers (6 percent or less) from control district.

All the providers acknowledged the individual benefits they acquired from the P4P. Acquiring new skills or receiving on-the-job training, developing team dynamics and interpersonal relations, psychological contentment, and earning extra income through incentive are some most frequently cited benefits. Regardless of the exposure to interventions, providers echoed the necessity of financial incentive for working in rural areas. Approximately half of the providers expected recognition for their performance in the form of training.

Opinions of respondents on how to sustain P4P-induced improvements centered on two innovations, quality assurance group and quality assurance team, for which ensuring manpower and refresher training of service providers and other staff are required. Provider expressed their apprehension that in the absence of incentive for providers, QAG visits are unlikely to make the facilities bring changes to the systems. They emphasized further strengthening of unit-based QATs within the facility to improve the services.

\section{GAPS IN SERVICE DELIVERY}

A total of 92 newborn and 2 maternal deaths occurred at the facilities of two districts during the three-month intervention period (March-May 2012) were systematically reviewed to determine the causes of deaths in an attempt to detect any flaws in the service delivery.

Delay to recognize a life-threatening condition or an emergency when births occur at home was found as the primary reason for newborn deaths. Several supply-side factors, like lack of inputs, e.g., technology or services necessary to provide critical care, unavailability of qualified providers (pediatrician) at referring facilities, and not fully complying treatment procedure contributed to a small proportion of deaths occurred at health facility.

Inadequate care women received at the community level and upon arrival at the facility contributed to maternal deaths. In particular, lack of skills among community-level providers to identify high-risk 
mothers, lack of inputs at the facility, e.g., blood transfusion, and unavailability of qualified providers (EOC-trained doctor) at receiving facilities were the key supply-side factors responsible for these deaths.

Facility-based death review process was not equipped to ascertain important community-level factors contributed to death in the facility. Facility-based review of deaths is thus fraught with an inherent weakness in identifying individual, cultural and societal factors which hinder women's access to timely and quality health care. Nevertheless, review of medical aspects of deaths provides a learning opportunity for providers, and generates recommendations for policymakers and program managers so that future morbidity and mortality can be averted through appropriate measures.

\section{COST OF MATERNAL HEALTH SERVICES}

A total of 14,662 maternal health service units (antenatal, delivery and postnatal care services) were delivered across the 12 facilities during March to May 2012. Altogether, 12 intervention facilities spent US\$68,651 in March to May 2012 quarter for providing incentives to the providers and fieldworkers and for acquiring essential drugs, supplies and consumables not being provided by the government system. Overall, per unit maternal health service cost stands at US $\$ 5$, with Gaibanda and Kurigram having the same unit cost of $\$ 6$ while Jamalpur District incurred the lowest unit cost of $\$ 3$.

Comparison of provider incentive cost incurred for each delivery by three performance-based financing initiatives reveals that incentive cost for each delivery under the P4P MRA project is US\$33, remarkably lower compared to the P4P OR project (US\$58) and much lower than the DSF program (US\$70). 


\section{LESSONS LEARNED}

Despite being a single quarter intervention directed towards model refinement and advocacy, P4Pinduced improvement in the performance in terms of increased service volume and improved quality of $\mathrm{MNCH}$ care was highly remarkable for the P4P MRA project. Six-month long P4P MRA project without measures of population-level outcome makes it implausible to state whether the approach is useful or not. Nevertheless, process evaluation generates several useful insights for policymakers and program managers.

- Team dynamics. P4P approach is a human resource innovation initiative in the health sector of Bangladesh where incentive is provided to motivate service providers at the institution level covering managers, direct and indirect service providers and administrative and support staff, contributing to ensure teamwork towards improving provider performance in reaching the targets within the stipulated time. Linking provider performance with both quantity and quality of services is a useful innovation for impacting the overall improvement of service delivery. However, the P4P model that rewards providers for achieving performance targets is not free from flaws. This model generates dissatisfaction among the providers when nonperformance of one unit affects the target achievement of the whole institution, preventing the performing units to get the reward. Distribution of incentives according to the performance of service units within the facility instead of measuring the performance of the whole facility may be an alternative.

- QAG and QAT innovations. The P4P initiative is highly acclaimed for introducing a systematic quality assurance mechanism through QAG and QAT in the health system. Acquiring new skills or receiving on-the-job training and developing team dynamics and interpersonal relations are the direct benefits of QAG and QAT innovations.

At the institution level, periodic visit by external higher-level body helps in identifying gaps in service delivery, ensuring regularity of services, providing mentoring, encouraging compliance with recommended clinical practice, and thus enhancing the provider capacity. Yet, QAG has a key deficiency of absence of outcome indicators in measuring quality of care. If modified, such a quality assurance mechanism can be employed for improving the monitoring of health service delivery at the district level and below in Bangladesh.

At the individual level, accountability of the providers is increased through unit-based QATs within the facility, as these teams review their own performance weekly and address internal quality gaps. Administration of the QAT tools within all service units is useful at the micro level, as these tools assess the readiness and requirements of a unit, expediting decisionmaking. Sustainability of this innovation largely rests on the regular coordination and supervision by facility managers.

- Supply-side inputs. Without ensuring key supply-side inputs, like availability of qualified providers (e.g., EOC-trained doctor and pediatrician) at the facilities and technology or services necessary to provide critical care (e.g., comprehensive EOC service with blood 
transfusion), it will be difficult to rapidly reduce the maternal and newborn deaths. Incentive may be counterproductive if required manpower, training and monitoring are not in place. Facilities also need to improve the infrastructure in case of increased client flow and higher bed occupancy in order to ensure better care. At the same time, developing skills among community-level providers to identify high-risk mothers is critical.

- Health information system. Existing MIS maintained by upazila and district level health facilities is not provisioned for gathering data on high-risk mothers, referral, family planning counseling, and health outcomes. Current system is not free from lapses since data are often not accessible and reliable because of manual collection and storage and duplication in the collection of data by two Directorates, making it difficult to measure actual performance of the facility. Introducing any performance-based incentive mechanism needs an MIS that is strengthened through inclusion new indicators, digitization of the recording keeping system, and coordination between Health and Family Planning Directorates.

- Inadequate project period. A six-month project with three-month intervention was peremptory in giving the flexibility to carry out advocacy activities for sensitizing policymakers for scaling up or adopting lessons learned. Within this brief period, it is too ambitious to conduct population-based evaluation to see changes in the outcomes of pregnant women.

Both P4P OR and P4P MRA have shown promise in increased uptakes of services, but they are challenged by the risk of sustainability. These projects completed the pilot phase and were valued for their contribution towards increasing institutional delivery, requiring less incentive cost for institutional delivery compared to that of the DSF program, and enhancing client satisfaction by reducing out-of-pocket expenses. Despite the brief implementation period, contribution of P4P interventions in rapidly raising the level of institutional deliveries flickers optimism towards meeting MDG of reducing maternal and infant mortality. 


\section{NEXT STEPS}

The P4P model offering incentives to a team of service providers has demonstrated high potential to enable the health facilities to increase service volume and to provide better quality of care. This model has also shown how to ensure accountability into the health system. The importance for continuing performance-based incentive program on maternal, newborn and child health care services is irrefutable, from two perspectives. First, such an initiative should be continued until it significantly increases institutional deliveries especially until the MDG targets are met. Second, continuing incentives for service providers cannot be withdrawn unless an alternative motivation is in place for the providers serving in rural areas. In low-performing areas with high level of maternal and newborn mortality, the performance incentive model needs to be implemented with a longer duration. It is urgently required to decide in what capacity performance-based incentive program should continue.

By using the lessons learned from both P4P OR and P4P MRA projects and with guidance from the MOHFW and in consultation with relevant stakeholders, a refined P4P model can be developed. Implementation of a refined $\mathrm{P} 4 \mathrm{P}$ project with the aim to compare cost effectiveness across $\mathrm{P} 4 \mathrm{P}$ and DSF models will enable the policymakers to make decisions on modification and scaling up of P4P and DSF models at the national level. Future P4P model needs to be implemented with a rigorous research design allowing measuring of the changes in health outcomes at the population level.

Alternatively, intensive advocacy should be in place to help the government to ensure utilization of the learning or experiences from the P4P initiative. In particular, the necessity of "quality of care" approach to improve maternal, newborn and child health services tested under the P4P scheme cannot be denied for the improvement of the monitoring of health service delivery in Bangladesh. In the context of growing importance on improving the quality of health services, DSF program can incorporate the QOC framework tested in the P4P project after necessary review and consensusbuilding. Additionally, there should be discussion on the possibility to modify the DSF scheme by replacing the individual incentive for providers with an institution-based incentive approach.

In pursuance of the MDGs of reducing maternal and neonatal mortality, the government needs to prepare itself to continue performance-based incentive program. Performance-based incentive is a transitional mechanism to expedite health outcomes. To sustain the improvements, a stronger health system with adequate and skilled human resources, regular supply of equipment and drugs, functional quality assurance system for mentoring and supervision, and strengthened MIS should be in place in addition to providing financial incentive for a certain period. 
Bangladesh Health Watch (BHW). 2008. "Health workforce in Bangladesh: Who constitutes the health care system." Dhaka: BHW, James P. Grant School of Public Health, BRAC university.

Chowdhury, M.H.R. 2008. "Neonatal deaths in a rural area of Bangladesh: An assessment of causes, predictors and health care seeking using verbal autopsy." Ph.D. dissertation, Curtin University of Technology, Western Australia.

Hatt, Laurel, Ha Nguyen, Nancy Sloan, Sara Miner, Obiko Magvanjav, Asha Sharma, Jamil Chowdhury, Rezwana Chowdhury, Dipika Paul, Mursaleena Islam, and Hong Wang. 2010. "Economic evaluation of demand-side financing (DSF) program for maternal health in Bangladesh." Bethesda, MD: Abt Associates Inc.

National Institute of Population Research and Training (NIPORT), MEASURE Evaluation, and ICDDR,B. 2011. Bangladesh Maternal Mortality and Health Care Survey 2010: Preliminary Results. Dhaka: NIPORT, MEASURE Evaluation, and ICDDR,B.

National Institute of Population Research and Training (NIPORT), Mitra and Associates, and ICF International. 2013. Bangladesh Demographic and Health Survey 2011. Dhaka, Bangladesh and Calverton, Maryland, USA: NIPORT, Mitra and Associates, and ICF International.

Rahman, Laila, Ubaidur Rob, Riad Mahmud, Ismat Ara Hena, Md. Noorunnabi Talukder and Md. Hafizur Rahman. 2011. "A pay-for-performance innovation integrating the quantity and quality of care in maternal, newborn and child health services in Bangladesh," P4P Final Report. Dhaka: Population Council.

Rob, Ubaidur, Md. Noorunnabi Talukder, and Tehmina Ghafur. 2006. "Health policies: Pledges and implementation." In "The State of Health in Bangladesh 2006: Challenges of Achieving Equity in Health." Dhaka: James P. Grant School of Public Health, BRAC University.

Talukder, Md. Noorunnabi, Ubaidur Rob, Laila Rahman, Ismat Ara Hena, and A.K.M. Zafar Ullah Khan. 2011. "A pay-for-performance model for increased utilization of maternal, newborn and child health services in Bangladesh," P4P Policy Brief. Dhaka: Population Council.

Talukder, Md. Noorunnabi and Ubaidur Rob. 2009. "Strengthening voice and accountability in the health sector." Workshop Report. Dhaka: Population Council.

UNICEF. 2008. The State of the World's Children 2009: Maternal and Newborn Health. New York: UNICEF. 


\section{APPENDIX}

Table A1. Changes in antenatal care service volume by study facilities

\begin{tabular}{lrrr}
\hline Facilities & $\begin{array}{r}\text { Quarterly Average } \\
\text { October'10- November'11 }\end{array}$ & $\begin{array}{r}\text { Quarterly Average } \\
\text { March- May 2012 }\end{array}$ & $\begin{array}{r}\text { Percentage difference } \\
\text { Gaibandha DH }\end{array}$ 278 \\
Sundarganj & 442 & 543 & $95 \%$ \\
Saghata & 861 & 961 & $117 \%$ \\
Fulchari & 362 & 1082 & $26 \%$ \\
Gaibandha District & 486 & 644 & $78 \%$ \\
Kurigram DH & 93 & $66 \%$ \\
Nageswari & 1010 & 216 & $131 \%$ \\
Bhurungamari & 454 & 858 & $-15 \%$ \\
Chilmari & 689 & 204 & $-55 \%$ \\
Kurigram District & 561 & 361 & $-48 \%$ \\
Jamalpur DH & 1529 & 410 & $-27 \%$ \\
Islampur & 562 & 1723 & $13 \%$ \\
Melandah & 825 & 653 & $16 \%$ \\
Bakshiganj & 693 & 926 & $12 \%$ \\
Jamalpur District & 902 & 954 & $38 \%$ \\
Thakurgaon DH & 704 & 1064 & $18 \%$ \\
Pirganj & 512 & 817 & $16 \%$ \\
Ranishankail & 823 & 314 & $-39 \%$ \\
Thakurgaon District & 680 & 766 & $13 \%$ \\
\hline Comparison sites & 680 & 766 & $13 \%$ \\
Intervention sties & 650 & 760 & $17 \%$ \\
\hline & & & $13 \%$ \\
\hline
\end{tabular}


Table A2. Changes in postnatal care service volume by study facilities

\begin{tabular}{lrrr}
\hline Facilities & $\begin{array}{r}\text { Quarterly Average } \\
\text { October'10- November'11 }\end{array}$ & $\begin{array}{r}\text { Quarterly Average } \\
\text { March- May 2012 }\end{array}$ & $\begin{array}{r}\text { Percentage difference } \\
\hline \text { Gaibandha DH }\end{array}$ 275 \\
Sundarganj & 151 & 426 & $55 \%$ \\
Saghata & 108 & 325 & $115 \%$ \\
Fulchari & 48 & 187 & $73 \%$ \\
Gaibandha District & 146 & 125 & $160 \%$ \\
Kurigram DH & 267 & 266 & $83 \%$ \\
Nageswari & 143 & 216 & $-19 \%$ \\
Bhurungamari & 73 & 72 & $-49 \%$ \\
Chilmari & 137 & 145 & $99 \%$ \\
Kurigram District & 155 & 179 & $31 \%$ \\
Jamalpur DH & 561 & 153 & $-1 \%$ \\
Islampur & 199 & 779 & $39 \%$ \\
Melandah & 158 & 377 & $89 \%$ \\
Bakshiganj & 295 & 232 & $47 \%$ \\
Jamalpur District & 303 & 465 & $58 \%$ \\
Thakurgaon DH & 712 & 463 & $53 \%$ \\
Pirganj & 235 & 869 & $22 \%$ \\
Ranishankail & 156 & 232 & $-1 \%$ \\
Thakurgaon District & 368 & 415 & $-26 \%$ \\
\hline Comparison sites & 368 & 405 & $10 \%$ \\
Intervention sites & 201 & 294 & $10 \%$ \\
\hline & & & $46 \%$ \\
\hline
\end{tabular}


Table A3. Comparison of quality score between pre-intervention and intervention by facilities

\begin{tabular}{|c|c|c|c|c|}
\hline District & Facility & $\begin{array}{r}\text { Pre-intervention } \\
\text { (March 2012) } \\
\text { quarter score (\%) }\end{array}$ & $\begin{array}{r}\text { Intervention } \\
\text { (June 2012) } \\
\text { quarter score (\%) }\end{array}$ & Change (\%) \\
\hline \multirow{4}{*}{ Gaibandha } & Gaibandha DH & 73 & 88 & 21 \\
\hline & Fulchhari UHC & 72 & 92 & 28 \\
\hline & Shaghata UHC & 80 & 93 & 16 \\
\hline & Sunderganj UHC & 68 & 88 & 29 \\
\hline \multirow{4}{*}{ Kurigram } & Kurigram DH & 81 & 91 & 12 \\
\hline & Chilmari UHC & 90 & 95 & 6 \\
\hline & Bhurungamari UHC & 83 & 95 & 14 \\
\hline & Nageshwari UHC & 86 & 91 & 6 \\
\hline \multirow{4}{*}{ Jamalpur } & Jamalpur DH & 78 & 84 & 8 \\
\hline & Melandah UHC & 82 & 88 & 7 \\
\hline & Bakshiganj UHC & 78 & 87 & 12 \\
\hline & Islampur UHC & 78 & 88 & 13 \\
\hline Intervention & & 79 & 90 & 14 \\
\hline \multirow{3}{*}{ Thakurgaon } & Thakurgaon DH & 56 & 61 & 9 \\
\hline & Ranishankail UHC & 56 & 68 & 21 \\
\hline & Porganj UHC & 68 & 63 & -7 \\
\hline Comparison & & 60 & 64 & 8 \\
\hline \multicolumn{2}{|c|}{$\begin{array}{l}\text { Percent difference between intervention } \\
\text { and comparison }\end{array}$} & 19 & 26 & \\
\hline
\end{tabular}

DH=District Hospital

UHC= Upazila Health Complex 